\title{
Brainstem Enkephalinergic Projections to Spinal Autonomic Nuclei
}

\author{
MaryAnn A. Romagnano, ${ }^{1,2}$ Raymond J. Harshbarger, ${ }^{1}$ and Robert W. Hamill ${ }^{1-4}$ \\ ${ }^{1}$ Neurology Unit, Monroe Community Hospital and the Departments of ${ }^{2}$ Neurology, ${ }^{3}$ Medicine, and ${ }^{4}$ Neurobiology and \\ Anatomy, School of Medicine and Dentistry, University of Rochester, Rochester, New York 14620
}

\begin{abstract}
The present studies in the rat employed a combined retrograde transport-immunocytochemical technique to determine the origin in the brainstem of enkephalin (Enk) projections to spinal sympathetic nuclei, including the intermediolateralis nucleus, pars principalis (ILP). We found that Enk projections to the ILp nucleus are found in such serotonergic-containing areas as the raphe obscurus; raphe pallidus; gigantocellular reticular nucleus, pars $\alpha$; paragigantocellular lateral nucleus; raphe magnus; and the rostral extension of the raphe magnus nucleus. The adrenergiccontaining rostroventrolateral reticular nucleus as well as the noradrenergic-containing areas A5, A7, ventral locus coeruleus, subcoeruleus, and fiber pathway linking the locus coeruleus and A5/A7 send Enk projections to ILp. In the pons, a large contralateral Enk projection to spinal sympathetic nuclei was found medial to the facial nerve and medial to the motor nucleus of the trigeminal nerve. These observations show the existence of a large number of Enk brainstem regions that can influence spinal autonomic centers via descending supraspinal projections.
\end{abstract}

Previous studies have revealed a ladderlike pattern of enkephalin (Enk) fibers in rat thoracolumbar spinal cord coinciding with the localization of nuclear groups containing sympathetic preganglionic neurons (Romagnano and Hamill, 1984). These studics provide an anatomical substrate at a spinal level for a functional relationship between the endogenous opioid Enk and the sympathetic nervous system. More specifically, they provide a morphologial basis for the hypothesis that the augmented sympathetic activity during opiate withdrawal occurs at a spinal level. Additional investigations employing spinal transections, hemisections, and dorsal and/or ventral rhizotomies have indicated that Enk fibers in thoracolumbar sympathetic nuclei are of both supraspinal and intraspinal origin (Romagnano et al., 1987). Enk-containing neurons are present throughout the brainstem, and in the dorsal horn and sympathetic nuclei in the spinal cord (Hokfelt et al., 1977a,b; Elde et al., 1978; Johansson et al., 1978; Sar et al., 1978; Uhl et al., 1979; Finley et al., 1981; Bennett et al., 1982; Dalsgaard et al., 1982; Senba et al., 1982;

\footnotetext{
Received Feb. 15, 1991; revised June 14, 1991; accepted June 17, 1991.

We sincerely thank Dr. Clifford Saper for teaching M.A.R. the methodology used in this report. Additionally, we are indebted to Dr. Saper for his helpful discussions of our results and review of the final manuscript. We also thank David K. Sundberg for the antiserum to enkephalin. This work was supported by the University of Rochester/Monroe Community Hospital Research Fund and by NIH Grants NS27197 to M.A.R. and NS22103 to R.W.H.

Correspondence should be addressed to MaryAnn Romagnano, Ph.D., Monroe Community Hospital, Neurology Unit, 3C-22, 435 East Henrietta Road, Rochester, NY 14620.

Copyright $\odot 1991$ Society for Neuroscience $0270-6474 / 91 / 113539-17 \$ 05.00 / 0$
}

Khachaturian et al., 1983; Romagnano and Hamill, 1984; Krukoff et al., 1985). Many brainstem regions containing Enk-immunoreactive neurons have direct projections to the intermediolateral cell column in thoracolumbar spinal cord (Basbaum et al., 1978; Amendt et al., 1979; Loewy et al., 1979; Loewy, 1981; Loewy and McKellar, 1981; Ross et al., 1981; Westlund et al., 1983; Skagerberg and Bjorklund, 1985; Blessing et al., 1987; Byrum and Guyenet, 1987; Charlton and Helke, 1987; Sasek and Helke, 1989; Sasek et al., 1990). Utilizing a combined retrograde transport-immunocytochemical technique, we sought to determine the sites of origin of Enk projections throughout the brainstem to spinal sympathetic nuclei. As such, it was our aim to suggest brainstem sites where the endogenous opioid Enk can influence spinal autonomic centers via descending supraspinal projections.

The present results represent the first description of the complete organization of the large number of enkephalinergic brainstem regions that can influence sympathetic activity via descending supraspinal projections. These results provide an anatomical framework by which brainstem endogenous opioids interact with the sympathetic nervous system and participate in cardiovascular regulation (Delle and Thoren, 1987; Li et al., 1988; Delle et al., 1990) and the autonomic nervous system response to stress (Naranjo et al., 1986; Nordin et al., 1987; Marson et al., 1989).

Parts of this work have previously been presented in abstract form (Romagnano et al., 1988).

\section{Materials and Methods}

Combined retrograde transport-immunocytochemical techniques were used to determine the distribution of brainstem Enk neurons projecting to autonomic regions of the thoracolumbar spinal cord. Seven female Sprague-Dawley rats were used in the first series of experiments, which employed Fast blue (FB) as the retrograde tracer. Four male and female Sprague-Dawley rats were used in a second series of experiments that employed rhodamine latex microspheres as the retrograde tracer. Following sodium pentobarbital anesthesia, all animals were placed in a stereotaxic apparatus, and the spinous processes and bony laminae of spinal segments T2 and T3 were exposed. A vertebral clamp (Kopf model 987) attached to the stereotaxic unit was clamped onto the T3 spinous process and gently drawn in a caudal direction in order to stabilize and slightly stretch the spinal cord. A unilateral nick was made in the meninges overlying the dorsal root entry zone in the intervertebral foramina between spinal segments T2 and T3. Using a $1 \mu$ l Hamilton syringe (\#7001-N), $200 \mathrm{nl}$ of a 5\% Fast blue (Sigma)-saline solution or $40 \mathrm{nl}$ of undiluted rhodamine latex microspheres was slowly injected into the spinal cord. The coordinates used for the intermediolateralis, pars principalis (ILp) nucleus (equivalent to the intermediolateral cell column) were 0.8 or $1.0 \mathrm{~mm}$ lateral to the midline, as determined by vasculature in the dorsal median fissure, and $1.1 \mathrm{~mm}$ ventral to the spinal cord surface. Following withdrawal of the syringe, the back muscles and skin were sutured. One to two weeks after surgery, the animals received an intraventricular injection of colchicine in order to improve 
visualization of immunoreactive neurons. The colchicine $(10 \mu \mathrm{l}, 15 \mathrm{mg} /$ $\mathrm{ml}$; Sigma) was injected into either the right or the left lateral ventricle at the following coordinates relative to bregma: $\mathrm{A} / \mathrm{P},-0.4 ; \mathrm{D} / \mathrm{V},-3.3$; $\mathrm{M} / \mathrm{L}, \pm 1.8$ (Pellegrino and Cushman, 1967). Within $36-48 \mathrm{hr}$ following colchicine administration, the animals were reanesthetized with sodium pentobarbital and perfused through the heart by using a modification of the pH shift method of Berod et al. (1981). The animals were first perfused with $250 \mathrm{ml}$ of $0.9 \%$ saline, followed by $500 \mathrm{ml}$ of $4 \%$ paraformaldehyde in $0.1 \mathrm{~m}$ phosphate buffer $(\mathrm{PB}), \mathrm{pH} 6.5$, and finally with $500 \mathrm{ml}$ of $4 \%$ paraformaldehyde in $0.1 \mathrm{M} \mathrm{PB}, \mathrm{pH} 8.5$. The entire brain and spinal cord from spinal levels $\mathrm{C} 3$ to $\mathrm{T} 5$ were immediately removed, posttixed for $60-90 \mathrm{~min}$ at room temperature in $4 \%$ paraformaldehyde in $0.1 \mathrm{M} \mathrm{PB}, \mathrm{pH} 8.5$, and then placed in a $0.1 \mathrm{M} \mathrm{PB}, \mathrm{pH} 7.4$, solution overnight at $4^{\circ} \mathrm{C}$. The next day, $40 \mu \mathrm{m}$ brainstem sections were cut using a Vibratome (Lancer) or a sliding microtome. Sections were collected in $0.1 \mathrm{M} \mathrm{PB}$-saline, pH 7.4 (PBS), and within $24 \mathrm{hr}$ were processed by the immunofluorescence method of immunohistochemistry to demonstrate the presence of Enk immunoreactivity. The sections were placed in primary antiserum used at a dilution of 1:500 or 1:1000 (IncStar, Inc., and Sundberg), overnight, at room temperature, on a rotator. The next day, sections were rinsed twice and incubated for $1 \mathrm{hr}$ at room temperature in a 1:50 dilution of fluorescein isothiocyanate (FITC)labeled goat anti-rabbit IgG antiserum (TAGO), followed by two additional rinses. All rinses and the diluent for the primary and secondary antisera consisted of $0.1 \mathrm{M}$ PBS, $3 \%$ normal goat serum, and $0.25 \%$ Triton X-100. Sections were mounted onto gelatin-coated slides, air dried, and coverslipped with Histoclad (Clay Adams; FB injections) or Fluoromount (Atomergic Chemetals Corp.; rhodamine latex microsphere injections). Slides were examined using an Olympus BHS System microscope equipped with a $\mathrm{BH} 2-\mathrm{RFC}$ reflected-light fluorescence attachment. Fluorescent cubic unit B was used for FITC fluorescence and contained a $490 \mathrm{~nm}$ exciter filter and a $515 \mathrm{~nm}$ barrier filter. An additional supplementary exciter filter, EY455 nm, was also used for FITC fluorescence. Rhodamine fluorescence cmployed the $\mathrm{G}$ cube with a 545 $\mathrm{nm}$ exciter filter and a $590 \mathrm{~nm}$ barrier filter. Fast blue fluorescence was observed with a UG1 exciter filter and a $420 \mathrm{~nm}$ barrier filter. In some cases, intense FB fluorescence could be visualized in cells under conditions used to observe FITC ("bleed through"). However, the appearance and in particular the color of these cells were distinct from singlelabeled Enk and double-labeled FB-Enk cells (M. Romagnano, R. J. Harshbarger, and R. Hamill, unpublished observations; C. B. Saper, personal communication).

Additionally, within 2-3 d of perfusion, serial $50 \mu \mathrm{m}$ horizontal Vibratome sections were cut from the spinal cord block. Spinal cord sections were stained with cresyl violet to determine the extent and localization of the Fast blue or rhodamine latex microsphere injection sites.

The Sundberg antiserum was generated in the rabbit with a methionine-enkephalin-thyroglobulin conjugate prepared by the dimethyl aminopropyl carbodiimide method. Although radioimmunoassay results indicate that the Sundberg antiserum has a higher affinity for leucine-enkephalin than for methionine-enkephalin, it does not distinguish between the two peptides. There is no significant cross-reactivity with $\beta$-endorphin, dynorphin (1-13), or dynorphin (1-8) (Sundberg and Dunlap, 1986). The IncStar antiserum to methionine-enkephalin (\#20065) was generated in rabbit against glutaraldehyde-hemocyanin and ethylEDI-hemocyanin conjugates. Both antisera resulted in identical Enk distribution patterns throughout the brainstem. Control absorption studies consisted of preincubation of $1 \mathrm{ml}$ of either of the two primary antisera (diluted $1: 1000$ ) with $10 \mu \mathrm{g}$ of synthetic methionine- or leucineenkephalin (Peninsula) or $5 \mu \mathrm{g}$ each of both methionine- and leucineenkephalin. All control absorption-treated sections were devoid of immunostaining.

Camera lucida drawings of individual brainstem sections from one rat (see Fig. 2) were used as a template and retrogradely labeled, and/ or Enk-immunoreactive neurons were plotted from the adjacent section onto the drawing outline.

\section{Results}

\section{Terminology}

We have used the atlas of Paxinos and Watson (1982) for defining nuclear regions within the brainstem. However, in many instances retrograde- and double-labeled neurons were found in brainstem regions known from previous studies to contain 5-HT, noradrenaline, or adrenaline neurons. In the case of 5-HT, the description of brainstem nuclear regions containing serotonergic cells is as described by Skagerberg and Bjorklund (1985, their Fig. 1). Descriptions of the localization of noradrenergic-containing cells and fibers in rat brainstem are from Dahlstrom and Fuxe (1964) and Palkovits and Jacobowitz (1974; their Figs. 15). Ross et al. (1984) describe the localization of the $\mathrm{C} 1$ adrenaline-containing neurons within the rostral ventrolateral medulla (their Fig. 1).

\section{Injection sites}

As described in Materials and Methods, the two retrograde tracers, FB and rhodamine latex microspheres (beads), were chosen to examine the distribution of brainstem neurons projecting to the spinal cord. Horizontal sections of spinal cord injection sites at the T2-T3 level using each retrograde tracer are shown in Figure $1, a$ and $b$. In Figure $1 a$, the fluorescent dye FB is found on the border of the lateral funiculus and the intermediate zone (arrowheads) at the same dorsal-ventral level as the sympathetic preganglionic-containing nucleus ILp (equivalent to the intermediolateral cell column; arrows). Although the injection site is centered around and includes several ILp cell clusters, there is spread of the dye medially within the intermediate zone and laterally to the lateral funiculus. At the same magnification as Figure $1 a$, Figure $1 b$ illustrates a rhodamine latex microsphere injection site. The rhodamine beads are restricted to the ILp nucleus (arrows) located at the border of the intermediate zone and the lateral funiculus (arrowheads). There is minimal spread of the beads within the lateral funiculus and intermediate zone (broken line). The injection sites photographed in Figure 1 are representative of the cases used in this study; that is, the FB or rhodamine beads are centered around the ILp cell clusters. If this criterion was not met, the animal was considered a control. The distribution patterns in the brainstem of retrogradely labeled cells resulting from control cases differed from the experimental cases detailed in this study. For example, the red nucleus was examined in experimental and control cases for the presence of retrogradely labeled cells. In none of the experimental cases and in only those control cases where the injection site was located within the lateral funiculus were retrogradely labeled neurons found in the red nucleus, indicating uptake by fibers in the rubrospinal tract.

The distributions of three types of labeled neurons are described in this study: (1) single-labeled Enk-containing brainstem neurons; (2) single-labeled FB or rhodamine bead-containing neurons, representing descending brainstem projections to sympathetic regions of the spinal cord, primarily the ILp nucleus; and (3) double-labeled Enk-FB- or Enk-rhodamine bead-containing ncurons representing brainstem enkephalinergic projections to sympathetic regions of the spinal cord, primarily the ILp nucleus. The brainstem distribution of the singlelabeled Enk neurons found in this study is similar to previous reports describing the localization of Enk neurons in the rat brainstem (Hokfelt et al., 1977a,b; Uhl et al., 1979; Finley et al., 1981; Khachaturian et al., 1983; Fallon and Leslie, 1986; Merchenthaler et al., 1986; Menetrey and Basbaum, 1987). Since the distribution pattern of Enk neurons within the brainstem is well established, we did not include a description of their localization in the text, nor did we plot single-labeled Enk neurons in Figure 2. 

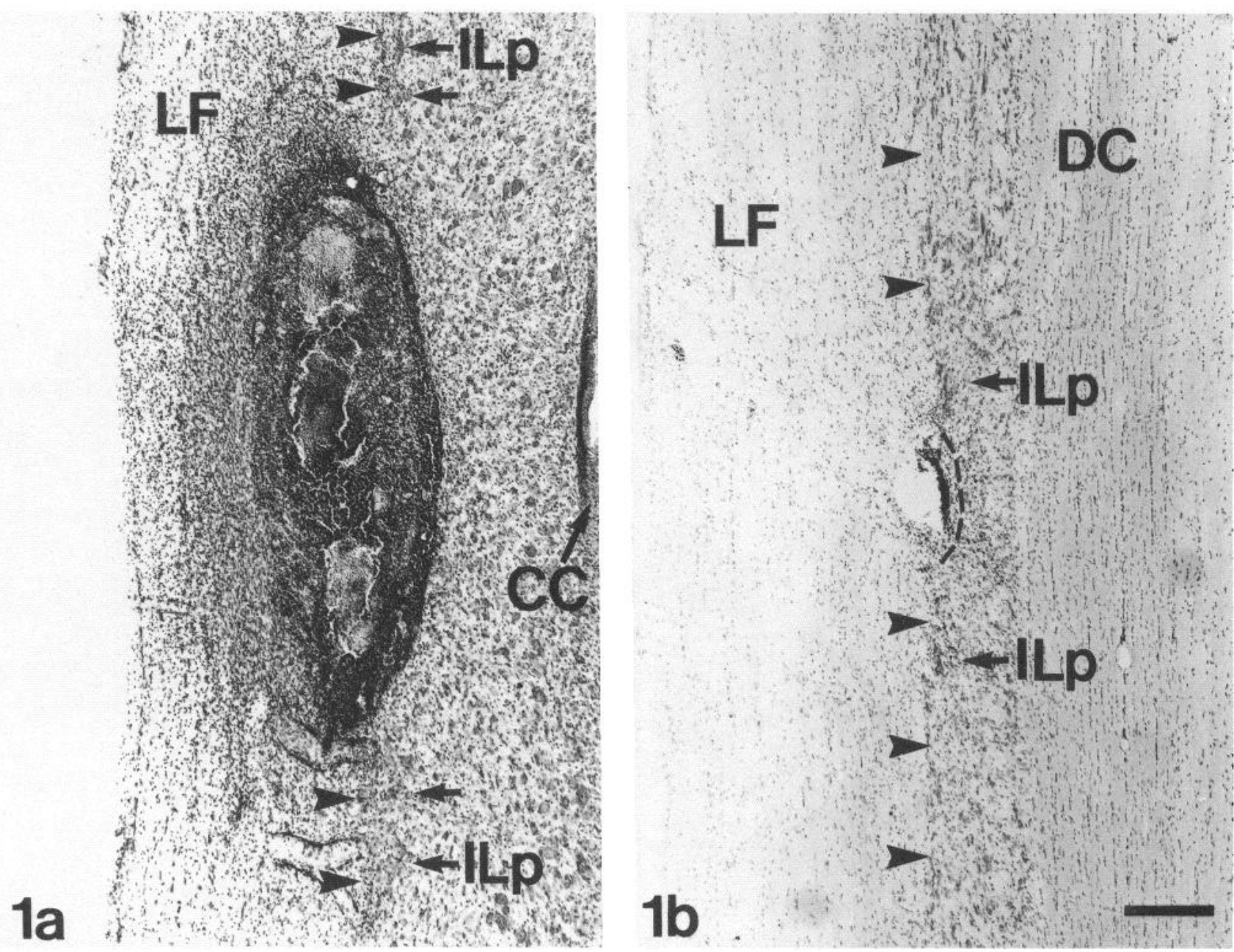

Figure 1. Horizontal sections of spinal cord injection sites at the T2-T3 level. $a$, The retrograde tracer FB is located on the border (arrowheads) of the lateral funiculus $(L F)$ and the intermediate zone at the same dorsal-ventral level as the sympathetic preganglionic-containing $I L p$ (arrows). The fluorescent dye is centered around and includes several ILp cell clusters; however, there is spread of the dye medially within the intermediate zone and laterally to the lateral funiculus. $b$, An example of a rhodamine latex microsphere injection site in the $I L p$ nucleus. The rhodamine beads are localized to the $I L p$ nucleus with minimal spread to the $L F$ and the intermediate zone. The broken line indicates the extent of the spread of the rhodamine beads within the intermediate zone. $C C$, central canal; $D C$, dorsal columns. Scale bar, $250 \mu \mathrm{m}$.

\section{Distribution of retrogradely labeled Fast blue- or rhodamine bead-containing brainstem neurons \\ Fast blue}

The retrograde tracer FB is intensely fluorescent within brainstem neurons filling primary and secondary dendrites. Retrogradely labeled FB neurons were found throughout the brainstem. Caudally, they are found at the junction of the medulla and spinal cord and extend rostrally to the midbrain (to the level of the inferior colliculus). FB-containing neurons were found predominantly ipsilateral to the spinal cord injection site, although all projections also had a bilateral origin. We found one major exception: a predominantly contralateral projecting pathway originated from the pontine tegmentum, medial to the fibers of the VIIth nerve and the motor nucleus of V.

At the brainstem-spinal cord junction (pyramidal tract decus- sation) and at the caudalmost extent of the hypoglossal nerve, FB-labeled neurons were found in the ventral medullary reticular nucleus (RV) (Fig. 2a,b). The adrenergic-containing rostroventrolateral reticular nucleus (RVL), as described by Ross et al. (1984), is located within the rostral ventrolateral medulla. The caudal border of the RVL is at the level of the area postrema where the "subtrigeminal and principal portions of the lateral reticular nucleus approach each other." The RVL extends rostrally to lie medial to the caudal pole of the facial nucleus. FBlabeled neurons were found throughout the entire rostrocaudal extent of the RVL (Fig. $2 c-h$ ). In addition, the commissural nucleus and the caudalmost solitarius nucleus contained occasional retrogradely labeled neurons (Fig. 2a,b).

Many retrogradely FB-labeled neurons were found in serotonergic-containing brainstem nuclei. In the caudal medulla, FB-containing neurons were found in the raphe obscurus (RO)

Figure 2. Drawings of individual brainstem sections from one rat illustrating the distribution of single-labeled FB-containing cells (open circles) and double-labeled FB-Enk-containing cells (solid circles) in the rat brainstem. Camera lucida drawings of individual brainstem sections from one rat were used as a template, and single- and double-labeled cells were plotted from the adjacent section onto the drawing outline. For abbreviations, see the Appendix. 


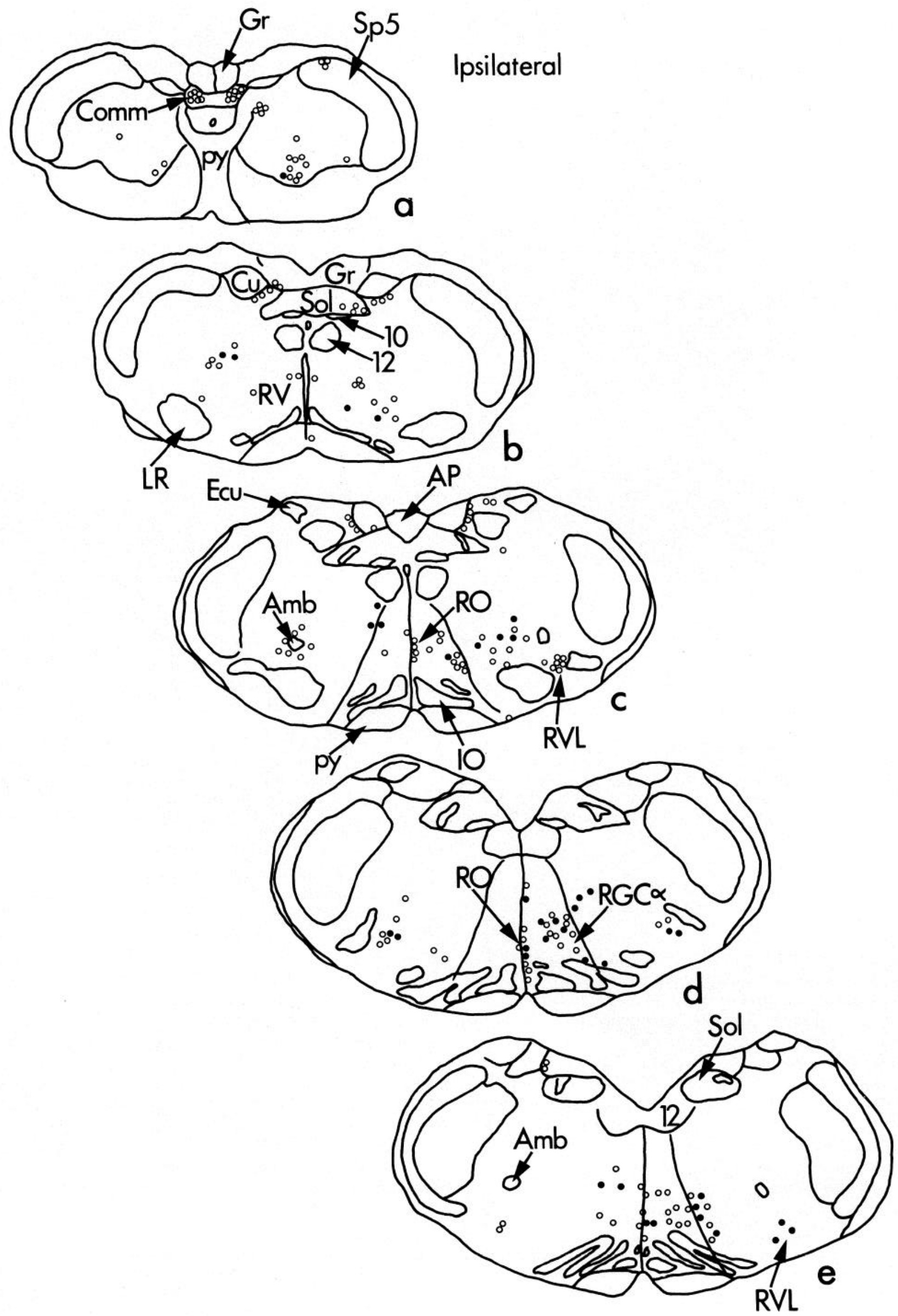




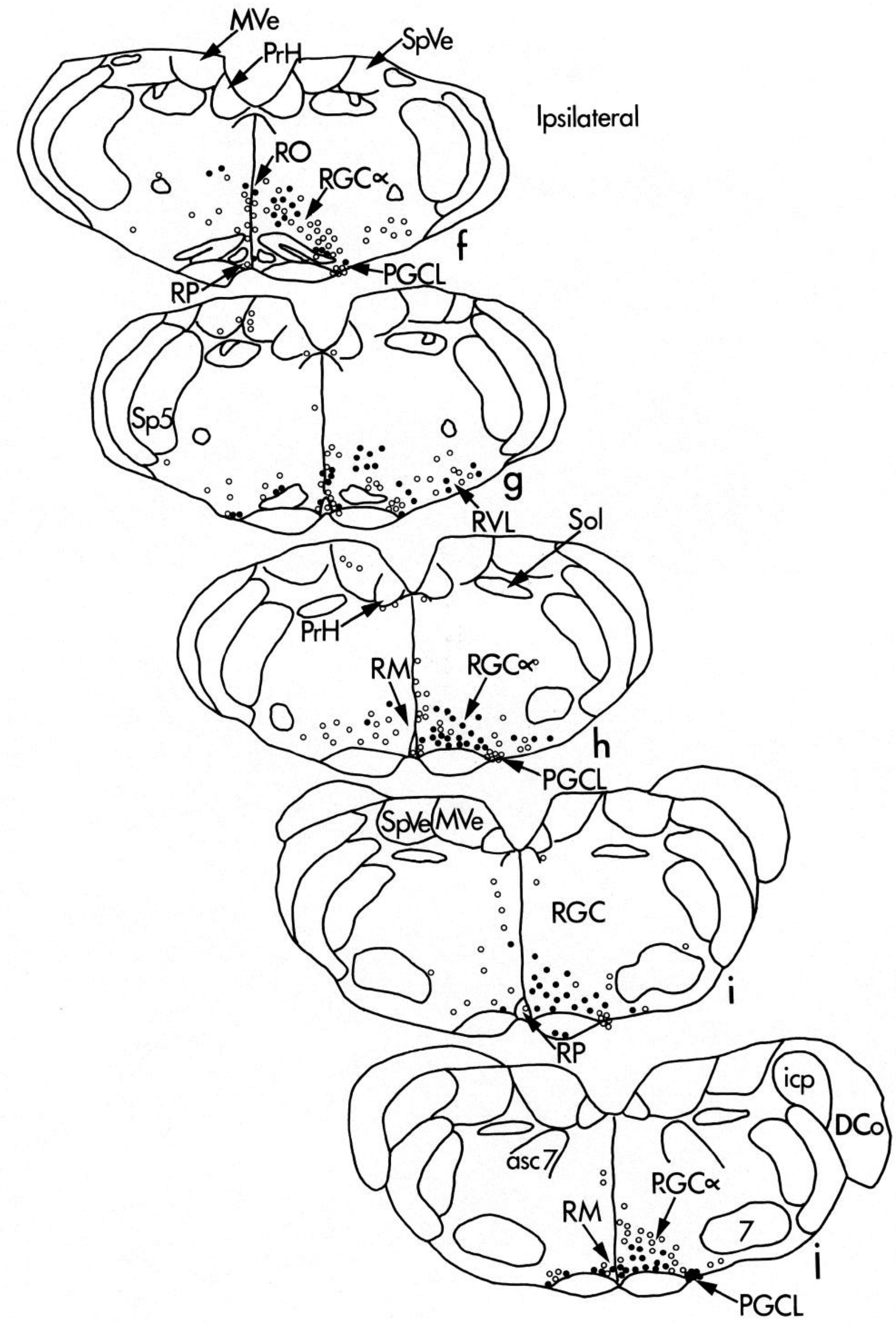




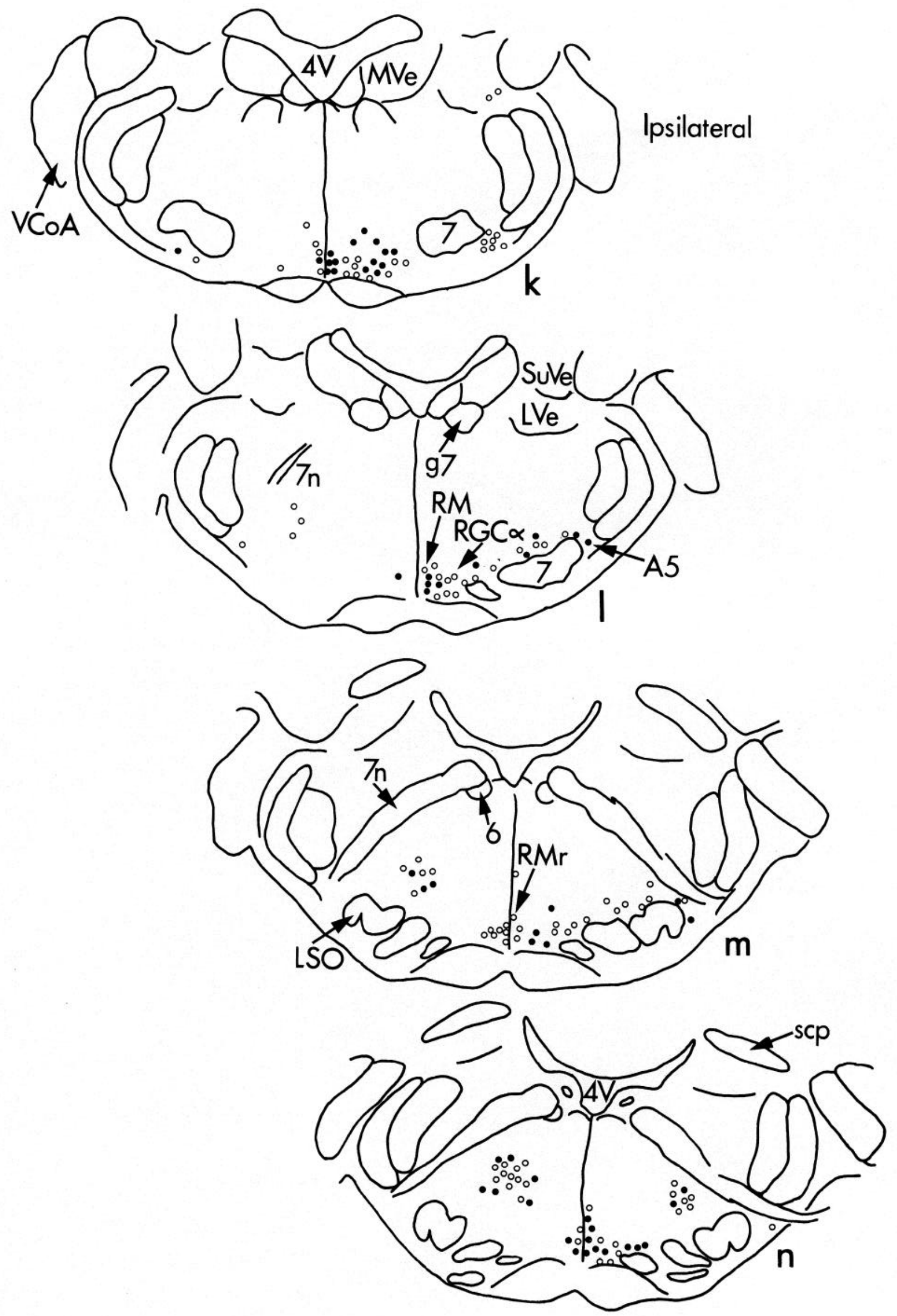




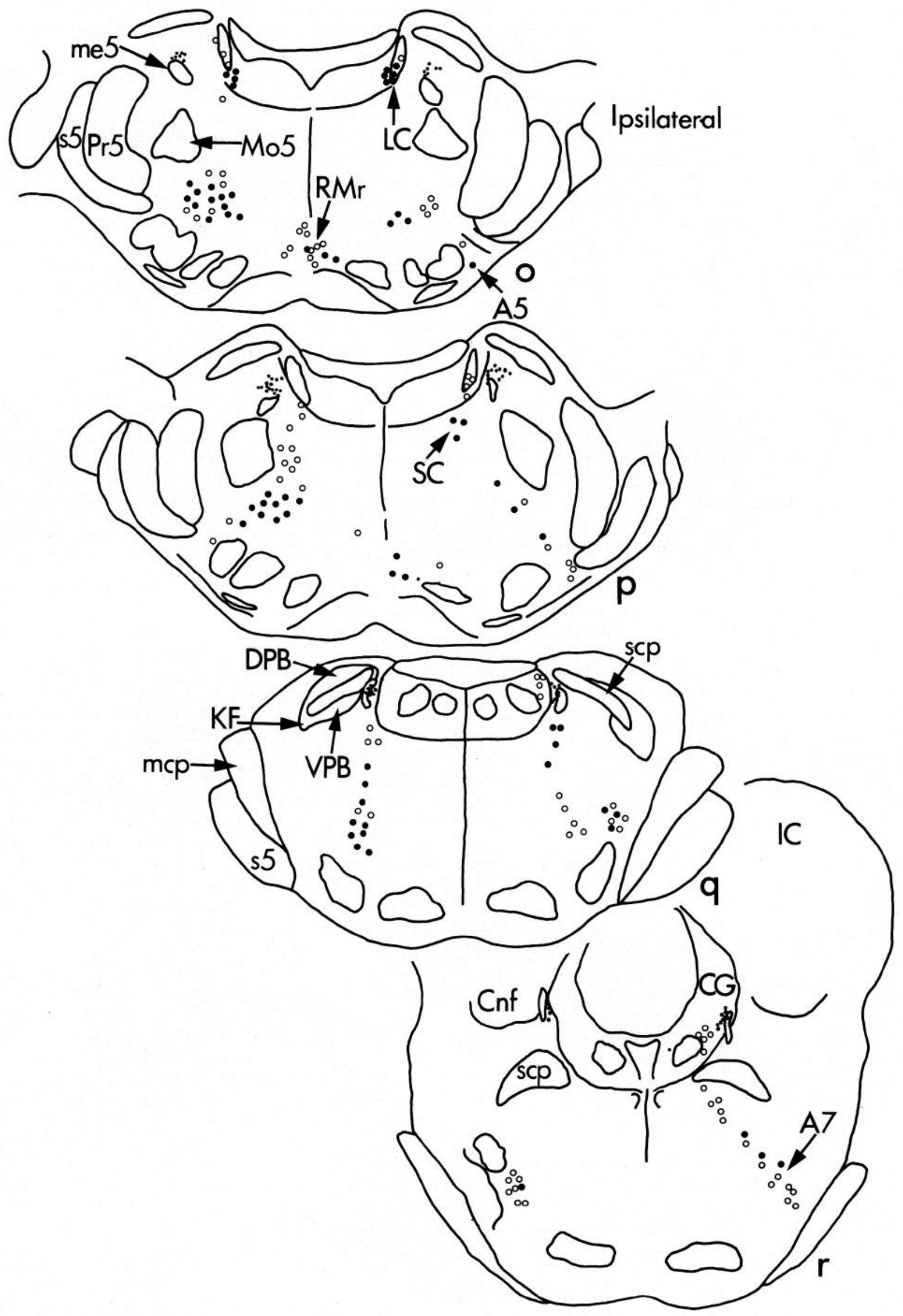


and raphe pallidus (RP) (Fig. 2c-f). Retrogradely labeled cells in the $\mathrm{RO}$ were located close to the midline and were generally fusiform in shape. FB-labeled RP neurons were usually small multipolar neurons. Many FB-labeled neurons were present throughout the entire length of the gigantocellular reticular nucleus (RGC), pars $\alpha$ (RGC $\alpha$ ) (Fig. $2 d-l$ ) and the paragigantocellular lateral nucleus (PGCL) (Fig. $2 f-j$ ). The RGC $\alpha$ is located dorsal to the inferior olive in the caudal medulla and extends to the rostral tip of the facial nucleus, where it is found dorsal to the pyramids. At the same rostrocaudal levels as the RGC $\alpha$, PGCL is found lateral to both the pyramids and $\mathrm{RGC} \alpha$, medial to the facial nucleus, and extends to the ventral surface of the brainstem. The raphe magnus (RM), in rostral medulla-lower pons, is located in the midline dorsal to the pyramids, bordered laterally by the RGC $\alpha$ and ventral to the RGC. A large number of retrogradely labeled neurons were found in the RM (Fig. $2 h-$ l). Cells containing FB in the RM were multipolar if located close to the midline, while labeled cells in the more laterallocated RGC $\alpha$ were fusiform in shape, with their long axis in the horizontal plane. The FB fusiform RGC $\alpha$-labeled cells most often lay just dorsal to the pyramids. FB-labeled cells in the PGCL were multipolar neurons of variable sizes. The rostral continuation of the RM into pontine levels is the rostral extension of RM nucleus (RMr). FB-labeled neurons were found in this midline group starting caudally at the level of the superior olive and extending rostrally to the trigeminal nuclear complex (Fig. $2 m-p$ ).

Retrogradely labeled FB neurons were found ventrolaterally in the pons at the level of the rostral half of the facial nucleus just medial to the ventral border of the spinal nucleus of $\mathrm{V}$ and lateral to the facial nucleus (Fig. $2 k, l)$. Farther rostrally, FBcontaining neurons were found in this same general location medial to the exiting VIIth nerve fibers (Fig. $2 m, n$ ). This area corresponds to the A5 noradrenergic region as described by Palkovits and Jacobowitz (1974). FB-containing neurons werc also found in the ventral part of the noradrenergic-containing locus coeruleus (A6) (Fig. 2o,p) and in the subcoeruleus nucleus (Fig. 2p,q). At the level of the inferior colliculus, the A7 cell group is found in the same general location in the ventrolateral pons as the A5 cell group. FB-labeled neurons were found in the $\mathrm{A} 7$ region (Fig. $2 r$ ). A band of FB-labeled cells extended between the locus coeruleus and the ventrolaterally located $A 5$ or A7 cell groups (Fig. $2 p, q$ ). The location of this band of retrogradely labeled neurons corresponds to a similar band of catecholamine fibers described by Palkovits and Jacobowitz (1974; their Figs. 2, 3).

Additionally, in the pontine tegmentum a large number of FB-containing neurons were found medial to the fibers of the VIIth nerve (Fig. $2 l-n$ ). This group of FB-labeled neurons extends rostrally within the pons and was found medial to the motor nucleus of V (Fig. 2o,p). Although this is a bilatcral spinal projection, the majority of retrogradely labeled neurons at this location were found contralateral to the injection site (see Fig. $2 n)$.

An occasional FB-labeled neuron was found in the commissural (Fig. $2 a$ ), solitary ( $2 b)$, lateral vestibular ( $2 k$ ), and RGC (2i) nuclei. In one case, several retrogradely labeled neurons were ipsilaterally found in the caudal Kolliker-Fuxe nucleus.

\section{Rhodamine latex microspheres}

Cells retrogradely transporting the rhodamine latex microspheres contained a punctate or granular fluorescence in cell bodies and proximal dendrites. Neurons containing rhodamine beads exhibited a predominant ipsilateral distribution in most of the same regions as the FB-containing neurons. That is, they were found in the RV and in the RVL. Many rhodamine beadlabeled neurons were present in the serotonergic-containing cell groups RO, RP, RGC $\alpha$, PGCL, RM, and RMr. The A5, A6 (locus coeruleus), and $\mathrm{A} 7$ noradrenergic cell groups contained rhodamine bead-labeled neurons. Bead-containing neurons were present in a band extending between the locus coeruleus and A5/A7 region. As with the FB spinal cord injections, a large number of rhodamine bead-labeled neurons were found contralateral to the injection site and were located just medial to the VIIth nerve or medial to the motor nucleus of $V$.

The distribution pattern of retrogradely labeled cells resulting from rhodamine bead spinal cord injections was identical to the results from FB injections, except the commissural, solitary, vestibular, and Kolliker-Fuxe nuclei did not contain labeled neurons following rhodamine bead injections.

\section{Distribution of FB-Enk- or rhodamine bead-Enk-containing brainstem neurons}

Double-labeled neurons containing a retrograde tracer and Enk were found bilaterally in brainstem nuclei; however, all nuclear groups had a predominant ipsilateral projection to the spinal cord (with one exception noted below).

\section{Fast blue-Enk}

In the caudal medulla, a small number of FB-Enk-containing neurons were found in the RV. FB-Enk neurons were present in the RVL at the rostral limit of the lateral reticular nucleus where the $\mathrm{Cl}$ adrenergic region merges with the more caudal A1 noradrenergic region (Fig. $2 d$ ). Continuing rostrally, FB-Enk neurons were found in RVL up to the level of the caudal pole of the facial nucleus (Fig. $2 h$ ). Of interest, single-labeled Enk neurons in the RVL were usually found lateral to the FB- and FB-Enk-containing cells.

FB-Enk neurons were located within serotonergic-containing nuclear groups in the medulla and pons. The RO contained FBEnk neurons throughout the medulla, while a small number of RP neurons were double labeled. A large number of FB-Enk neurons were found in the $\mathrm{RGC} \alpha$ located dorsal to the inferior olive at the level of the exiting XIIth nerve and extending up to the caudal pole of the facial nucleus (Figs. $2 d-h, 3 a, b$ ). Throughout the extent of the facial nucleus, FB-Enk neurons in the RGC $\alpha$ were found medial to the facial nucleus and lateral to the RM (Fig. 2i-k). At the same rostrocaudal levels as $\mathrm{RGC} \alpha$, the PGCL nucleus is located lateral and ventral to the $\mathrm{RGC} \alpha$ and contained FB-Enk neurons (Fig. $2 f-j$ ). A large number of FB-Enk neurons were found in the RM (Figs. $2 h-l, 3 c, d$ ) and continued rostrally in the RMr (Fig. $2 m-p$ ). As with FB-containing cells, FB-Enk neurons in the RM were multipolar if close to the midline, while the more laterally placed cells dorsal to the pyramid in the RGC $\alpha$ were fusiform in shape.

At the caudal pole of the superior olive, FB-Enk neurons were seen in the noradrenergic-containing A5 region located medial to the exiting VIIth nerve fibers and lateral to the rostral facial nucleus/superior olive (Fig. $2 l-p$ ). As with FB-labeled neurons, double-labeled neurons were found in the ventral region of the locus coeruleus, the subcoeruleus, and along the noradrenergic fiber pathway in the pons extending between the locus coeruleus and A5/A7 region (Fig. $2 p-r$ ). A small number of FB-Enk cells were found in the $A 7$ region in the rostral pons-caudal midbrain 

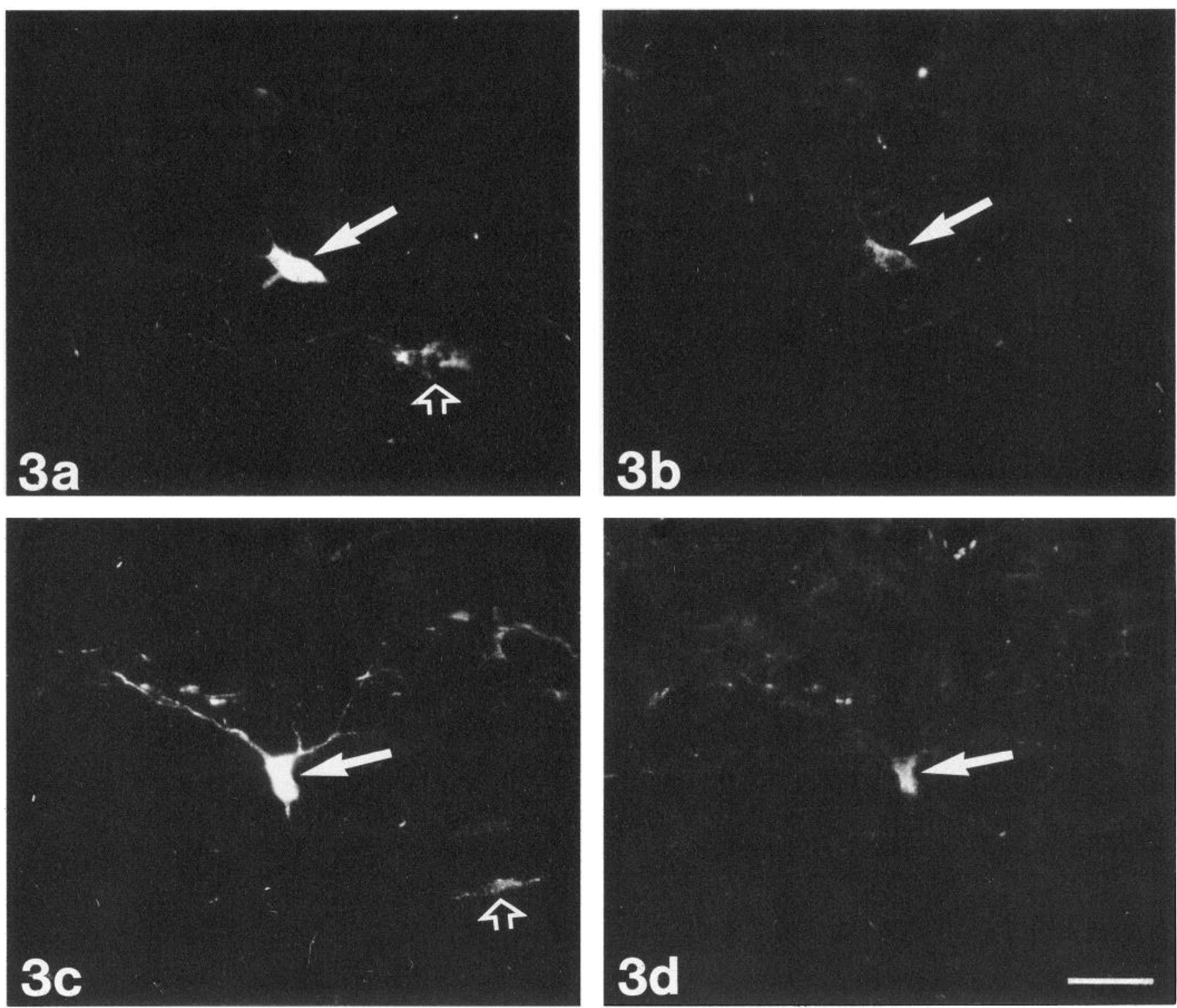

Figure 3. Examples of double-labeled FB-Enk-containing cells in the rat brainstem. In $a$, a neuron in the RGC $\alpha$ nucleus contains the retrograde tracer FB (solid arrow). In $b$, the same neuron contains the opioid peptide Enk (arrow). RGC $\alpha$ neurons that contain the retrograde tracer FB but do not contain Enk are indicated by the open arrow in $a$. An FB-containing cell in the RM nucleus is indicated in $c$ (solid arrow). This same neuron also contains Enk as shown in $d$ (arrow). A single-labeled FB-containing cell in the RM is indicated in $c$ by the open arrow. Scale bar, $50 \mu \mathrm{m}$.

(Fig. 2q,r). As mentioned previously, in the pontine tegmentum, there was a large Enk-containing contralateral and smaller ipsilateral projection to the spinal cord located medial to the VIIth nerve or farther rostrally medial to the motor nucleus of $\mathrm{V}$ (Fig. $2 m-p)$.

\section{Rhodamine bead-Enk}

Although rhodamine bead-Enk-containing neurons were located bilaterally within several brainstem nuclear groups, the majority of rhodamine bead-Enk-containing neurons were located ipsilateral to the injection site. A smaller number of brainstem double-labeled neurons resulted from spinal cord injections of rhodamine beads compared to FB injections at the same level. Neurons containing rhodamine beads and Enk were found in the medulla in the RO. An occasional rhodamine bead-Enk cell was found in the RP. The RGC $\alpha$ nucleus contained many rhodamine bead-Enk neurons (Fig. $4 a, b$ ). These double-labeled neurons were located caudally in the medulla among the rootlets of the XIIth nerve dorsal to the inferior olive. Farther rostrally, rhodamine bead-Enk neurons were found in the RGC $\alpha$ dorsal to the pyramid and medial to the facial nucleus. The greatest number of rhodamine bead-Enk neurons were found in the RM (Fig. $4 c, d$ ). These multipolar neurons were found in the midline dorsal to the pyramids. Rhodamine bead-Enk neurons lateral to the RM in the RGC $\alpha$ were fusiform in shape.

A small number of rhodamine bead-Enk neurons were found in the noradrenergic A5 region and within the noradrenergic pathway extending between A5/A7 and the locus coeruleus. Again, the newly described contralateral projection from the pontine tegmentum medial to the VIIth nerve and the motor nucleus of $\mathrm{V}$ contained rhodamine bead-Enk neurons (a small number of double-labeled neurons were present ipsilaterally to these same areas).

Contrary to results with FB spinal cord injections, rhodamine 

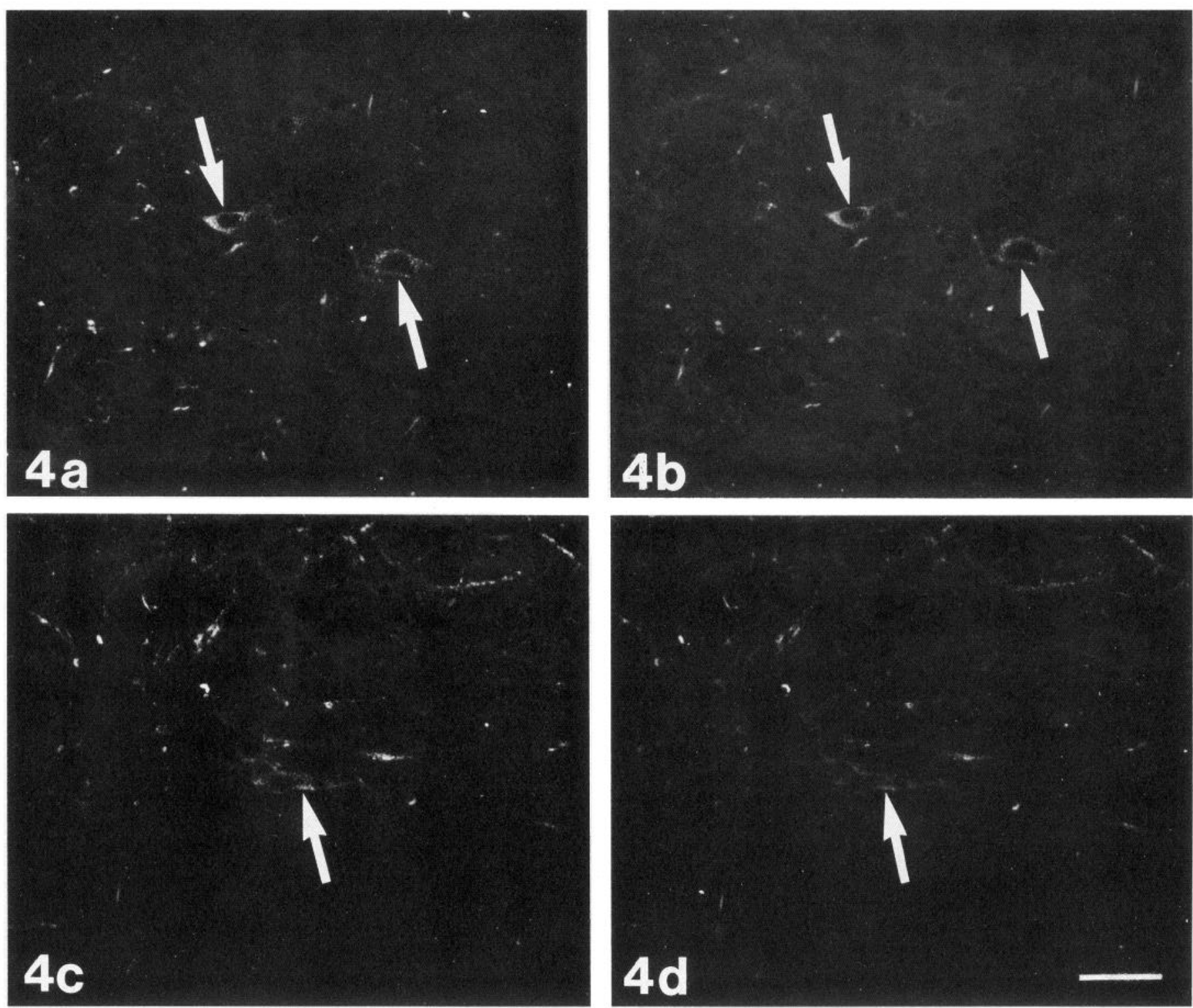

Figure 4. Examples of double-labeled rhodamine bead-Enk-containing cells in the rat brainstem. $a$ and $b$, Arrows indicate the same neurons containing rhodamine beads $(a)$ and Enk $(b)$ in the RGC $\alpha . c$ and $d$, Rhodamine beads are contained in neurons of the RM $(c$, arrow); this same cell is shown to be enkephalinergic ( $d$, arrow). Scale bar, $50 \mu \mathrm{m}$.

bead injections in the present study did not retrogradely label Enk neurons in the RVL nucleus and the locus coeruleus/subcoeruleus regions.

\section{Discussion}

The results of the present study, using a combined retrograde transport-immunocytochemical technique, have elucidated the brainstem distribution of enkephalinergic neurons that project to thoracolumbar spinal cord sympathetic regions, primarily the ILp nucleus. These results are summarized in Figure 5. Additionally, the locations within the brainstem of single retrogradely labeled neurons are described and represent the origin of nonenkephalinergic descending supraspinal inputs to spinal cord ILp. Double-labeled neurons were located bilaterally in those brainstem regions projecting to the ILp; however, the majority of supraspinal Enk projection neurons were present ipsilateral to the injection site. Neurons containing the retrograde tracer
FB and the opioid peptide Enk were found in RVL, the C1 adrenergic-containing region (Fig. 5, pathway 3 ). Throughout the medulla and pons, Enk neurons projecting to the spinal cord were found in regions known to contain 5-HT neurons; these include the RO, RP, RGC $\alpha$, PGCL, RM, and RMr (Fig. 5, pathways 1 and 2). In the ventrolateral pons, double-labeled neurons were present in the A5 and A7 noradrenergic-containing regions. The ventral locus coeruleus and subcoeruleus contained spinal-projecting FB-Enk neurons. Double-labeled neurons were found among the band of noradrenergic fibers extending between the locus coeruleus dorsally and the A5/A7 region ventrally (Fig. 5, pathway 4). Our results have also indicated a large contralateral supraspinal Enk projection located medial to the VIIth nerve and medial to the motor nucleus of $\mathrm{V}$ in the pontine tegmentum (Fig. 5, pathway 5).

Sympathetic preganglionic neurons are found in five nuclear groups in the spinal cord (Petras and Cummings, 1972). The 
most prominent nuclear group is the ILp nucleus located on the border of the intermediate zone and the lateral funiculus. The ILp nucleus is arranged in cell clusters and exhibits a periodicity of $300 \mu \mathrm{m}$ at the T2-T3 spinal cord level. This nuclear group is equivalent to the intermediolateral cell column. Additional preganglionic neurons are located within the lateral funiculus [nucleus intermediolateralis, pars funicularis (ILf)] and intermediate zone [nucleus intercalatus (IC) and pars paraependymalis (ICpe)] and dorsal to the central canal (dorsal commissural nucleus). In order to produce an injection site confined to the ILp nucleus, two retrograde tracers were chosen, FB and thodamine latex microspheres. Both retrograde traccrs are rcadily transported and are compatible with immunocytochemical methods. One major difference between the two tracers is that compared to FB, rhodamine beads show very little diffusion when injected into brain tissue and thus result in small, welldefined injection sites (Katz et al., 1984). Therefore, to produce an injection site confined to one or two preganglionic ILp cell clusters, we chose to use rhodamine beads (Fig. 1b). However, as described above, preganglionic sympathetic neurons are not solely located in the ILp nucleus. In order to present a retrograde tracer to a greater number of supraspinal afferents, we chose FB. FB produces a well-defined injection site (Fig. $1 a$ ), but as a result of minimal diffusion and an increased volume of FB injected compared to the rhodamine beads, the area of tracer uptake was extended to 8-10 preganglionic cell clusters and perhaps preganglionic neurons in the IC and ILf nuclei. However, because of the periodicity of preganglionic ncurons in the ILp, ILf, and IC nuclei, the presence of FB in the lateral funiculus and the intermediate zone raises the possibility that retrogradely labeled neurons in the brainstem may project to areas other than the sympathetic nuclei.

Although the FB injection sites were larger compared to the rhodamine bead injection sites, the distribution of retrogradely labeled neurons in the brainstem was similar with a few minor exceptions. A small number of FB-containing neurons were found in the commissural, solitary, vestibular, and Kolliker-Fuxe nuclei that were not present following rhodamine bead injections. Descending tracts from these nuclear groups are present in the lateral funiculus (Kuypers, 1981), and it is possible that portions of these tracts were damaged at the injection site resulting in $\mathrm{FB}$ being retrogradely transported in the damaged axons. Alternatively, one or more of these groups may project to preganglionic neurons in the intermediate zonc or lateral funiculus, regions where FB was present, but not the rhodamine beads. There is evidence, in the cat, for solitariospinal and commissural-spinal projections to the ILp and IC nuclei (Loewy and Burton, 1978). Saper and Loewy (1980) and Fulwiler and Saper (1984) suggested that non-catecholamine-containing neurons in the caudal Kolliker-Fuxe nucleus project to the intermediolateral cell column.

The distribution of FB-Enk neurons was similar to the distribution of rhodamine bead-Enk neurons with two exceptions. The locus coeruleus and the RVL did not contain double-labeled neurons following rhodamine bead injections, whereas doublelabeled neurons were present in these nuclear groups following FB injections. It has been reported that noradrenergic and nonnoradrenergic locus coeruleus neurons project to the thoracic spinal cord (Tohyama et al., 1979; Blessing et al., 1981; Westlund et al., 1983; Fritschy et al., 1987; Stanfield, 1989; Fritschy and Grzanna, 1990); however, it is uncertain whether these fibers, especially noradrenaline-containing fibers, terminate in

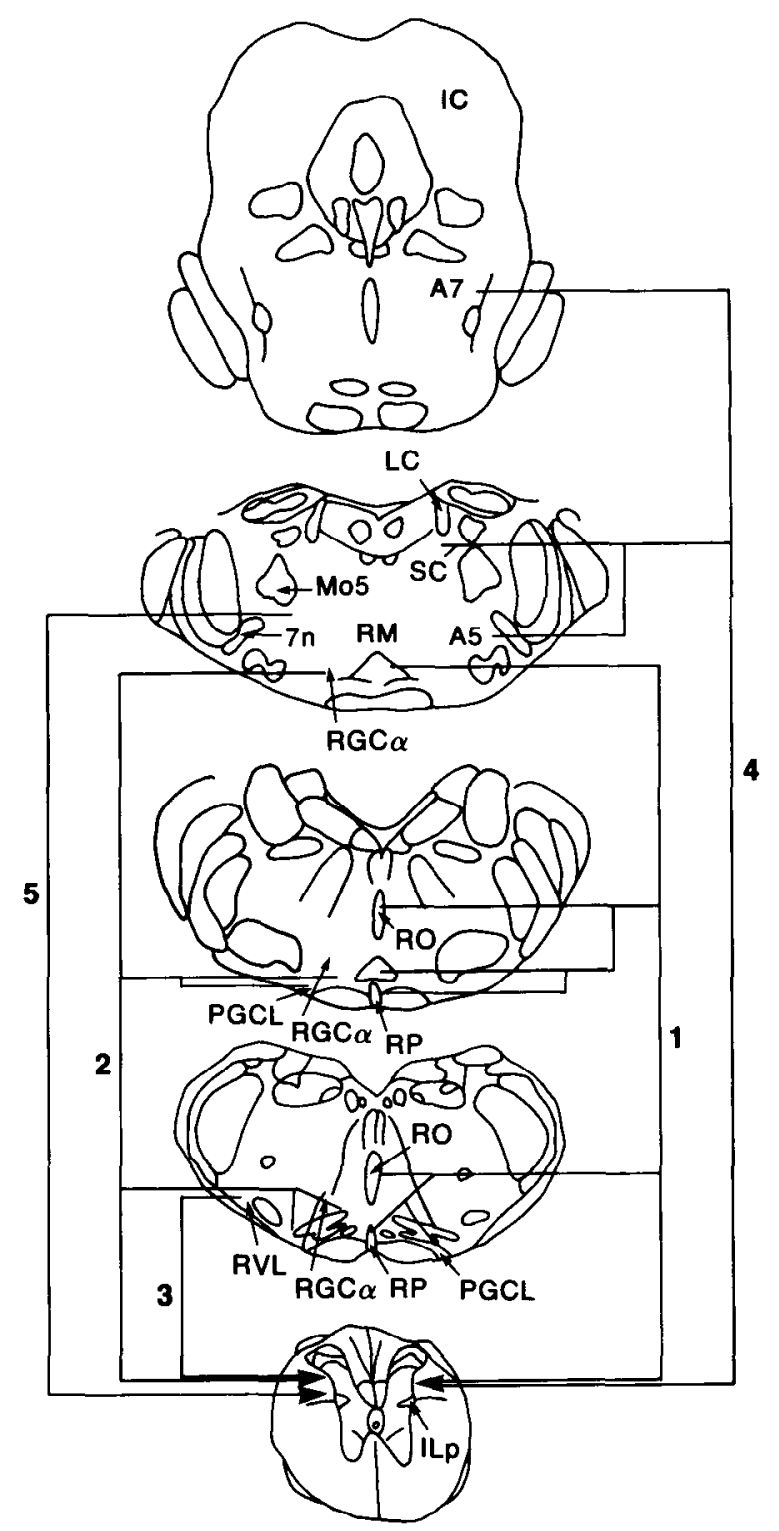

Figure 5. Drawings of representative brainstem sections (from top, Figs. 31, 34, 37, and 40 from Paxinos and Watson, 1982) are used to illustrate the location of Enk-containing neurons that project to the ILp nucleus. Double-labeled neurons are found in serotonergic-containing regions $(1,2)$ and in the RVL medulla (3). The noradrenergic-containing $A 5, A 7$, ventral locus coeruleus $(L C)$, and subcoeruleus $(S C)$ nuclei send enkephalinergic projections to the $I L p(4)$, as do the regions located medial to the facial nerve and motor nucleus of the trigeminal nerve (5). For other abbreviations, see the Appendix.

the ILp nucleus (Westlund et al., 1982; Fritschy et al., 1987; Fritschy and Grzanna, 1990). Although we report rhodamine bead-containing single-labeled cells in the locus coeruleus, it is possible that the reason that we did not observe Enk-rhodamine bead-containing neurons in the locus coeruleus or adjacent structures is due to the small size of the rhodamine injection site and perhaps the existence of a relatively sparse Enk coerulospinal projection. FB-Enk neurons are found in the RVL, while Enk-labeled rhodamine bead-containing neurons could not be found in this nucleus. Previous studies have shown adrenergic-containing $\mathrm{Cl}$ neurons and nonadrenergic neurons in RVL to project to the ILp (Ross et al., 1981; McKellar and Loewy, 1982). In agreement, we observed single-labeled FB- 
and rhodamine bead-containing neurons in the RVL. Again, due to the small volume of rhodamine beads injected in the spinal cord, the Enk projection from RVL to ILp may have been missed. Alternatively, it is possible that Enk projections from both the locus coeruleus and RVL to the ILp do not exist but were present following FB injections as a result of uptake and retrograde transport of FB from damaged axons at the injection site.

There are many nuclear regions in the brainstem where Enk neurons are found, all of which could represent potential sites of origin of the Enk innervation seen in spinal sympathetic nuclei (Hokfelt ct al., 1977a,b; Johansson et al., 1978; Sar et al., 1978; Finley et al., 1981; Khachaturian et al., 1983). Several reports have shown many of these regions to contain Enk neurons that project to the spinal cord. For example, in the rat, spinally projecting Enk neurons were found in the RP, RM, and adjacent areas of the reticular formation (Bowker et al., 1981, 1983). Hokfelt et al. (1979) described Enk-immunoreactive neurons immediately dorsal to the inferior olive in the $\mathrm{RGC} \alpha$ that project to the lower thoracic-upper lumbar spinal cord. Enkcontaining spinally projecting neurons have also been identified in the rat in the RO; RP; RM; interfascicularis hypoglossi nucleus, pars dorsalis; and the magnocellular reticular nucleus (Menetrey and Basbaum, 1987). In the ventral medulla in the rat, Enk neurons projecting to lower cervical cord were found in the RP, RM, and PGCL nuclei (Millhorn et al., 1987). In the above reports, the exact site in the spinal cord to which these doublelabeled ncurons project was not detcrmined since the injection sites were large and not confined to a single spinal nuclear group. A single report has described, in the rat, Enk projections from the ventral medulla to ILp (Sasek and Helke, 1989). In this study, rhodamine beads were injected and confined to the ILp nucleus at the T3 spinal cord level (their Fig. 2). Enk neurons that project to the ILp were found in the magnocellular reticular nucleus, the paragigantocellular reticular nucleus, the RM, and the parapyramidal region. The terminology employed by Sasek and Helke (1989) of the ventral medullary reticular nuclei was based on descriptions by Newman (1985) and Andrezik and Beitz (1985). At the same rostrocaudal level illustrated in Sasek and Helke's report (1989), we describe the FB-Enk and rhodamine bead-Enk-labeled cells in the RM, RGC $\alpha$, and PGCL nuclei (Fig. $2 h-j$ ). Our definitions of the locations of ventral medullary reticular nuclei are based primarily on Skagerberg and Bjorklund's (1985) description of serotonergic-containing brainstem nuclei. The RGC $\alpha$ nucleus corresponds to the magnocellular reticular nucleus, pars $\alpha$, and the ventral portion of the magnocellular reticular nucleus, pars $\beta$, of Newman (1985) or the gigantocellular nucleus, pars $\alpha$, and the dorsal portion of the paragigantocellular reticular nucleus of Andrezik and Beitz (1985). The descriptions of the boundaries of the RM in Newman (1985), Andrezik and Beitz (1985), and Skagerberg and Bjorklund (1985) are approximately the same. In the present study, double-labeled neurons were found in the PGCL nucleus located lateral to $\operatorname{RGC} \alpha$ and pyramids, medial to the facial nucleus, and extending to the ventral surface of the brainstem. The PGCL nucleus corresponds to the parapyramidal region of Sasek and Helke (1989) or the ventral portion of the paragigantocellular nucleus of Andrezik and Beitz (1985). Although our report and Sasek and Helke (1989) employ different terminology for the reticular nuclear groups in the ventral medulla, it is clear that both reports describe Enk neurons projecting to ILp in the same locations.

In addition to the reticular nuclei in the ventral medulla, many other nuclear groups have been described as projecting to ILp. The present data describe single-labeled FB- and rhodamine bead-containing cells and double-labeled FB-Enk cells in the RVL medulla. In agreement, previous studies have shown that the medullary ventrolateral reticular formation projects bilaterally to the ILp nucleus in the rat (Loewy et al., 1981; McKellar and Loewy, 1982; Ross et al., 1984; Guyenet and Young, 1987), and Ross et al. (1981) demonstrated adrenaline-containing neurons in the $\mathrm{Cl}$ group of the RVL medulla that project to the thoracic spinal cord. Additional investigations indicate that the $\mathrm{Cl}$ group is the origin of adrenergic fibers in the ILp, IC, and dorsal commissural nuclei (Ross et al., 1981, 1984). Within C1, many phenylethanolamine- $N$-methyltransferase-containing cells also contain Enk (Ceccatelli et al., 1989), suggesting corelease of these two substances in the spinal cord. The results from the present and previous studies establish the existence of a projection from the RVL medulla to the spinal sympathetic nuclei. Most of this projection is adrenergic; however, the present study suggests that part of this pathway is enkephalinergic.

In the present study, following both FB and rhodamine bead injections in ILp, single-labeled and double-labeled cells were found in the RO, RP, RGC $\alpha$, PGCL, RM, and RMr nuclei. In agreement, Sasek and Helke (1989) describe Enk cells projecting to the ILp in the RM, parts of the RGC $\alpha$, and PGCL; however, this is the first report of an Enk projection from the RO, RP, and $\mathrm{RMr}$ nuclei to ILp. Our findings support autoradiographic and electron microscopic studies demonstrating projections from the RO, RP, and RM nuclei to the ILp nucleus (Basbaum et al., 1978; Holstege et al., 1979; Loewy, 1981; Loewy and McKellar, 1981; Bacon et al., 1990). Many neurons in the raphe nuclear complex and adjacent reticular formation nuclei contain 5-HT (Dahlstrom and Fuxe, 1964; Skagerberg and Bjorklund, 1985). Serotonergic cells in the RO, RP, RM, and RGC $\alpha$ have been shown to project to the spinal cord (Bowker et al., 1981, 1983; Araneda et al., 1989) or more specifically to the ILp (Loewy and McKellar, 1981). Skagerberg and Bjorklund (1985) have identified serotonergic and non-serotonergic neurons in the RO, RP, RM, PGCL, and RMr nuclei projecting to the ILp nucleus. The results from these studies agree with our results demonstrating medullary raphe nuclei and adjacent reticular nuclei projections to ILp, although many of these projections contain 5-HT. Enk and 5-HT have been shown to coexist in neurons of the raphe complex (Glazer and Basbaum, 1981; Leger et al., 1986). Bowker et al. (1983), in a quantitative study, suggest that a large number of raphe neurons projecting to the spinal cord contain 5-HT along with one or more peptides, including Enk. Interestingly, in our study in the RM, single retrogradely labeled and double-labeled neurons were multipolar but acquired a more fusiform shape when located in the RGC $\alpha$ nucleus. Skagerberg and Bjorklund (1985) described a similar appearance to 5-HTcontaining cells in these two nuclei. It is uncertain whether Enk neurons projecting to ILp contain 5-HT, although the similarity in their appearance suggests this might be the case. At the very least, we feel our results indicate a large Enk projection to the ILp from serotonergic-containing nuclear groups in the rat brainstem.

In the present study, FB-Enk- and rhodamine bead-Enk-containing neurons were found in the ventrolateral pontine tegmentum lateral to the caudal facial nerve nucleus and at a more rostral level lateral and dorsolateral to the superior olivary nucleus. This region has been identified by Dahlstrom and Fuxe (1964) and Palkovits and Jacobowitz (1974) as the noradrenaline-containing A5 region. Additionally, we saw both types of 
double-labeled neurons in the noradrenergic-containing A7 region that were found in the same location as the A5 region, but in the rostral pons and caudal midbrain. Noradrenaline-containing cells in the $\mathrm{A} 7$ region were also found in the subcoeruleus and extended from the ventral edge of the locus coeruleus to the ventrolateral border of the brainstem (Dahlstrom and Fuxe, 1964). We saw double-labeled neurons in these locations also (Fig. $2 p, q$ ). To our knowledge, this is the first report of an enkephalinergic projection from the A5 and A7 regions to the ILp nuclei in rat spinal cord. Previous studies using anterograde autoradiographic methods have demonstrated the existence of a projection from the $A 5$ and $A 7$ regions to the ILp and IC nuclei in the rat (Loewy et al., 1979; Byrum and Guyenet, 1984; Coote, 1985; Byrum et al., 1987). Fritschy and Grzanna (1990) have shown that A5 and A7 fibers terminate in the ILp while non-noradrenaline-containing cells projecting to the spinal cord are found ventral and lateral to the locus coeruleus, that is, in the same location where we saw single-labeled and double-labclcd cclls. Loewy et al. (1979) demonstrated noradrenergic cells in the A5 group projecting to the thoracic ILp and IC nuclei, whereas Westlund et al. $(1981,1983)$ have shown that noradrenergic fibers in the thoracic ILp originate from pontine noradrenergic cell groups primarily in the $A 7$ region, with a smaller projection from the A5 region. Fritschy and Grzanna (1990) determined that both the A5 and A 7 cell groups are the source of noradrenergic axons in the ILp. Although Enk cells are present in the A5 and A7 cell groups (Finley et al., 1981), no evidence has been presented to indicate that Enk and noradrenaline (tyrosine hydroxylase) coexist in these neurons. In fact, Khachaturian et al. (1983) noted the dissimilar location of leucine-Enk neurons and tyrosine hydroxylase-immunoreactive neurons in the A5 noradrenergic cell group (their Fig. 7), indicating that in at least the $A 5$ region opioid peptides and noradrenaline may not coexist.

In the present study, FB- and rhodamine bead-containing neurons were found in the ventral portion of the locus coeruleus. FB-Enk- but not rhodamine bead-Enk-labeled neurons were also found in the same location. Our retrograde transport results support the findings of Westlund et al. (1983) and Loughlin et al. (1986) who demonstrated, in the rat, a ventral locus coeruleus projection to the spinal cord. Fritschy et al. (1987), using combined anterograde transport-immunocytochemical methods, reported noradrenaline locus coeruleus projections to the superficial laminae of the dorsal horn, intermediate zone, and lamina $\mathrm{X}$ in the spinal cord. The majority of noradrenaline locus coeruleus axons present in the dorsal horn and intermediate zone originate from the central and ventral caudal portion of the locus coeruleus (Fritschy and Grzanna, 1990). According to these authors, noradrenaline projections to ILp do not originate from the locus coeruleus but from the $\mathrm{A} 5$ and $\mathrm{A} 7$ regions. The existence of non-noradrenaline locus coeruleus projections to ILp was not examined. As stated above, we were unable to see retrogradely labeled Enk cells in the locus coeruleus following our rhodamine bead ILp injections. Therefore, we are uncertain of the existence of an Enk projection from the locus coeruleus to ILp even though Enk and noradrenaline coexist in cat locus coeruleus neurons (Charney et al., 1982). In the present study, single retrogradely labeled cells were present in the ventral locus coeruleus following injection of either tracer into the ILp nucleus. In the animals receiving FB injections, these results could be due to spread of the dye at the injection site subsequent to retrograde transport from injured axons. This is possible since Fritschy et al. (1987) observed ventral locus coeruleus projec- tions to the intermediate zone. However, since spread of the rhodamine beads was minimal and confined to the ILp, it is hard to explain the presence of rhodamine bead-containing neurons in the ventral locus coeruleus as being due to uptake by damaged axons at the injection site.

Another new finding in this report is the presence of a large contralateral Enk projection to ILp originating in the region just medial to the VIIth nerve and farther rostrally medial to the motor nucleus of V. Double-labeled neurons are also located in these same regions ipsilateral to the injection site. It is unclear whether these regions are considered part of the A5, A6 (locus coeruleus), and A7 noradrenaline-containing cell groups. As described by Dahlstrom and Fuxe (1964), some cells belonging to the A5 group were found "along the medial side of the $n$. facialis, dorsal to the tractus rubro-spinalis." Dahlstrom and Fuxe (1964) also discussed noradrenaline-containing cells as part of the A6 group located ventral to the "rostral portion of the locus coeruleus in an arch medial to the nuc. motorius n. trigemini down to the cells within group A5." Ilowever, in the present study, retrogradely labeled Enk cells in these regions were found in a well-circumscribed area (Fig. $2 m-o$ ); that is, not along an arch between the A6 and A5 groups. Khachaturian et al. (1983) described Enk-immunoreactive cells within the vicinity of the motor nucleus of $\mathrm{V}$ and scattered throughout the pontine reticular formation (their Fig. 1, level - 1.4). Preproenkephalin gene expression demonstrated by in situ hybridization histochemistry is present medial to both the VIIth nerve and the motor nucleus of V (Morita et al., 1990; their Fig. 6, levels 5 and 6). Leong et al. (1984, their Figs. 2, 3, 5) and Westlund et al. (1982, their Fig. $4 B$ ) found retrogradely labeled neurons medial to both the exiting VIIth nerve and motor nucleus of V following large injections of HRP into rat spinal cord. Few studies in the rat have examined the origin of pontine and mesencephalic descending projections to the ILp or thoracic spinal cord. It may be that the existence of supraspinal projections originating from the pons or mesencephalon is included in the literature describing A5, A6, and A7 spinal cord efferents as reviewed above. Nonetheless, our results indicate the existence of a predominantly contralateral Enk projection to ILp originating from the regions medial to the VIIth nerve and motor nucleus of $\mathrm{V}$ in rostral pons and caudal midbrain.

In addition to Enk, other neurotransmitters are present in bulbospinal projections to ILp. Charlton and Helke (1987) demonstrate medullary substance P (SP) projections to the ILp nucleus in the PGCL nucleus (adjacent and lateral to the pyramidal tract), ventral reticular nucleus, pars $\alpha$ (lateral and dorsal to the inferior olive), and the RP. The neurotransmitters thyrotropinreleasing hormone, SP, and 5-HT are present in neurons in the ventral medulla and project to ILp (Sasek et al., 1990). Many of these neurons contain one, two, or three of these neurotransmitters and are located in the RP; RM; magnocellular reticular nucleus, pars $\alpha$; paragigantocellular reticular nucleus; and the parapyramidal region (Sasek et al., 1990; terminology discussed above). Sasek and Helke (1989) have shown that, with the exception of the RM, the Enk and SP neurons in the ventral medulla that project to ILp share a similar distribution pattern. However, they found little evidence for coexistence of Enk and $\mathrm{SP}$ in these neurons. Although future studies are needed to examine coexistence of Enk with other neurotransmitters in brainstem neurons that project to ILp, our data and others suggest the coexistence of peptidergic and classical neurotransmitters and allow for the possibility of chemical coding of descending projections to ILp. 
Electrophysiological studies in the cat have revealed several brainstem sites that contain neurons that are involved in the origin and generation of sympathetic nerve activity. Gebber, Barman, and colleagues (Gebber and Barman, 1985, 1988; Barman and Gebber, 1987, 1989; Gebber et al., 1990) used spiketriggered averaging of inferior cardiac postganglionic sympathetic nerve discharge to identify single brainstem neurons with sympathetic nerve activity. These neurons are classified as sympathoexcitatory (or sympathoinhibitory) if their firing rate is decreased (or increased) during baroreceptor receptor reflex activation. Sympathoexcitatory neurons are found in the RVL, while sympathoinhibitory neurons are found in the caudal medullary raphe complex. The lateral tegmental field of the dorsal medulla contains both sympathoexcitatory and sympathoinhibitory neurons. Antidromic mapping shows that sympathoexcitatory neurons in the RVL and sympathoinhibitory neurons in the raphe innervate the intermediolateral nucleus, while neurons in the lateral tegmental field do not project to the spinal cord. Sympathoexcitatory neurons in the lateral tegmental field exert their effect via a projection to the RVL spinal sympathoexcitatory neurons, while sympathoinhibitory neurons in the lateral tegmental field project to the raphe spinal sympathoinhibitory neurons. These physiological findings support our tracer results showing a projection from the RVL and caudal raphe to the intermediolateral nucleus (ILp) and, in addition, assign a function to these projections. The present study has also shown that part of this supraspinal projection from the RVL and the caudal raphe to ILp is enkephalinergic. Thus, sympathoexcitatory and sympathoinhibitory supraspinal influences may be mediated via Enk, although the exact role Enk plays in the generation and origin of sympathetic nerve activity is unknown.

The present and previous studies demonstrate that Enk is present in descending brainstem Enk projections to sympathetic preganglionic neurons, providing a site for the possible interaction between endogenous opioids and the sympathetic nervous system. Li et al. (1988) have shown that intrathecal injections of $\mathrm{D}-\mathrm{Ala}^{2}$-D-Leus-enkephalin (DADLE) into the subarachnoid space at the $\mathrm{T} 9$ level in chloralose-anesthetized rats results in naloxone-reversible inhibitory cardiovascular effects. Intrathecal DADLE administration caused dose-dependent hypotension and bradycardia ( $\mathrm{Li}$ et al., 1988). These authors suggest that "intrathecal injection of DADLE inhibits central sympathetic activity possibly at a spinal locus." In agreement, the physiological studies of Franz et al. (1982) demonstrate that the depressant effects of opiates on spinal sympathetic preganglionic activity are routed through both an intraspinal excitatory pathway and a spinal reflex pathway. Delle and Thoren (1987) examined sympathetic nerve activity, heart rate, and blood pressure during naloxone-precipitated morphine withdrawal reactions in morphine-dependent rats. The results of their study suggest that $\delta$-opioid receptors may mediate a tonic excitatory input on renal sympathetic nerves. Additionally, Delle ct al. (1990) suggest that the sympathetic nervous system responds differentially during naloxone-precipitated morphine withdrawal in anesthetized rats. That is, sympathetic nerve activity is increased to the adrenal gland and in the lumbar sympathetic chain, while renal nerve activity is inhibited. These results indicate possible facilitatory and inhibitory interactions between Enk and opioid receptors and the regulation of regional sympathetic output. On the other hand, Rochford and Henry (1990) feel that, in the rat, the intravenous or intrathecal administration of leucine-Enk and the resulting hypertensive effect was not mediated via an opioid mechanism since it is not blocked by naloxone. Instead, the increase in arterial pressure following intrathecal administration of methionine-Enk or leucine-Enk to the second or ninth thoracic spinal segment is mediated via a non-opioid mechanism.

In summary, our results reveal new data on the distribution of brainstem Enk projections to the spinal cord including the ILp nucleus: the originating nuclear groups were found bilaterally in several regions throughout the medulla, pons, and caudal midbrain. Neurons containing a retrograde tracer and Enk were found in the RVL (Fig. 5, pathway 3), the A5 and A7 regions, ventral locus coeruleus, and subcoeruleus and along the pathway linking the locus coeruleus and the A5/A7 regions (Fig. 5, pathway 4). A prominent contralateral Enk projection to ILp was found medial to the VIIth cranial nerve and farther rostral medial to the motor nucleus of V (Fig. 5, pathway 5). Throughout the medulla and pons, retrogradely labeled Enk neurons were found in the raphe (RO, RP, RM, RMr), RGC $\alpha$, and PGCL nuclei (Fig. 5, pathways 1 and 2). These observations suggest specific brainstem sites where the endogenous opioid Enk can influence spinal autonomic centers via descending supraspinal projections. Furthermore, our results suggest that the medulla, pons, and midbrain as well as the spinal cord contain multiple sites that may participate in Enk-sympathetic interactions. In addition, the results from this study provide the anatomical evidence for physiological findings suggesting that opioids act centrally to influence brainstem involvement in autonomic functions. Many of the brainstem sites containing spinally projecting Enk neurons also contain other neurotransmitters, such as 5-HT, SP, noradrenaline, or adrenaline. This coincidence allows speculation as to the possible interactions/involvement between these neurotransmitters and the Enk projection to the sympathetic preganglionic-containing ILp nucleus. In the peripheral sympathetic nervous system, frequency-dependent chemical coding of neurotransmission exists: high-frequency and bursting activity preferentially releases neuropeptide $Y$, which is cocontained with the classical neurotransmitter norepinephrine (Lundberg et al., 1986). Conceivably, the rate and pattern of central firing may determine the release of the neuropeptide Enk. Further research will show whether such a hypothesis is tenable and also whether catecholamine-, indolamine-, or peptide-containing neurons differentially influence the descending Enk input to spinal sympathetic centers, via such mechanisms as presynaptic inhibition or facilitation.

$\begin{array}{ll}\text { Appendix } \\ \text { Abbreviations } \\ 4 \mathrm{~V} \quad \text { fourth ventricle } \\ 6 & \text { abducens nucleus } \\ 7 & \text { facial nucleus } \\ 7 \mathrm{n} & \text { facial nerve } \\ 10 & \text { dorsal motor nucleus of the vagus } \\ 12 & \text { hypoglossal nucleus } \\ \mathrm{Amb} & \text { ambiguus nucleus } \\ \text { AP } & \text { area postrema } \\ \text { asc7 } & \text { ascending fibers of facial nerve } \\ \mathrm{CG} & \text { central gray } \\ \mathrm{Cnf} & \text { cuneiform nucleus } \\ \mathrm{Comm} & \text { commissural nucleus } \\ \mathrm{Cu} & \text { cuneate nucleus } \\ \text { DCo } & \text { dorsal cochlear nucleus } \\ \text { DPB } & \text { dorsal parabrachial nucleus } \\ \text { Ecu } & \text { external cuneate nucleus }\end{array}$

\section{Appendix}

4V fourth ventricle

6 abducens nucleus

7 facial nucleus

$7 \mathrm{n}$ facial nerve

10 dorsal motor nucleus of the vagus

12 hypoglossal nucleus

$\mathrm{Amb} \quad$ ambiguus nucleus

Comm

$\mathrm{DCo}$

Ecu 
g7 genu facial nerve

Gr gracile nucleus

IC inferior colliculus

IO inferior olive

icp inferior cerebellar nucleus

KF Kolliker-Fuxe nucleus

LC locus coeruleus

LR lateral reticular nucleus

LSO lateral superior olive

$\mathrm{LVe} \quad$ lateral vestibular nucleus

mcp middle cerebellar peduncle

me5 mesencephalic tract, trigeminal nerve

Mo5 motor nucleus, trigeminal nerve

MVe medial vestibular nucleus

PGCL paragigantocellular lateral nucleus

$\operatorname{Pr} 5 \quad$ principal sensory nucleus, trigeminal nerve

PrH prepositus hypoglossal nucleus

py pyramidal tract

RGC gigantocellular reticular nucleus

$\mathrm{RGC} \alpha \quad$ gigantocellular reticular nucleus, pars $\alpha$

RM raphe magnus nucleus

$\mathrm{RMr}$ rostral extension of the raphe magnus nucleus

RO raphe obscurus nucleus

RP raphe pallidus nucleus

RV ventral medullary reticular nucleus

RVL rostroventrolateral reticular nucleus

s5 sensory root, trigeminal nerve

SC subcoeruleus nucleus

scp superior cerebellar peduncle

$\mathrm{Sp} 5 \quad$ spinal nucleus, trigeminal nerve

SpVe spinal vestibular nucleus

Sol solitary nucleus

$\mathrm{SuVe} \quad$ superior vestibular nucleus

VCoA ventral cochlear nuclcus, antcrior

VPB ventral parabrachial nucleus

\section{References}

Amendt K, Czachurski J, Dembowsky K, Seller H (1979) Bulbospinal projections to the intermediolateral cell column: a neuroanatomical study. J Auton Nerv Syst 1:103-117.

Andrezik JA, Beitz AJ (1985) Reticular formation, central gray and related tegmental nuclei. In: The rat nervous system (Paxinos $G$, ed), pp 1-28. New York: Academic.

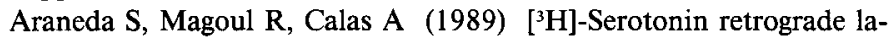
belling in serotonergic fibers. Brain Res Bull 22:951-958.

Bacon SJ, Zagon A, Smith AD (1990) Electron microscopic evidence of a monosynaptic pathway between cells in the caudal raphe nuclei and sympathetic preganglionic neurons in the rat spinal cord. Exp Brain Res 79:589-602.

Barman SM, Gebber GL (1987) Lateral tegmental field neurons of cat medulla: a source of basal activity of ventrolateral medullospinal sympathoexcitatory neurons. J Neurophysiol 56:1410--1424.

Barman SM, Gebber GL (1989) Lateral tegmental field neurons of cat medulla: a source of basal activity of raphespinal sympathoinhibitory neurons. J Neurophysiol 61:1011-1024.

Basbaum AI, Clanton CH, Fields HL (1978) Three bulbospinal pathways from the rostral medulla of the cat: an autoradiographic study of pain modulating systems. J Comp Neurol 178:209-224.

Bennett GJ, Ruda MA, Gobel S, Dubner R (1982) Enkephalin immunoreactive stalked cells and lamina IIb islet cells in cat substantia gelatinosa. Brain Res 240:162-166.

Berod A, Hartman BK, Pujol JF (1981) Importance of fixation in immunocytochemistry: use of formaldehyde solution at variable $\mathrm{pH}$ for the localization of tyrosine hydroxylase. J Histochem Cytochem 29:844-850.

Blessing WW, Goodchild AK, Dampney RAL, Chalmers JP (1981) Cell groups in the lower brain stem of the rabbit projecting to the spinal cord, with special reference to catecholamine-containing neurons. Brain Res 221:35-55.

Blessing WW, Oliver JR, Hodgson AH, Joh TH, Willoughby JO (1987) Neuropeptide Y-like immunoreactive $\mathrm{Cl}$ neurons in the rostral ventrolateral medulla of the rabbit project to sympathetic preganglionic neurons in the spinal cord. J Auton Nerv Syst 18:121-129.
Bowker RM, Steinbusch HWM, Coulter JD (1981) Serotonergic and peptidergic projections to the spinal cord demonstrated by a combined retrograde HRP histochemical and immunocytochemical staining method. Brain Res 211:412-417.

Bowker RM, Westlund KN, Sullivan MC, Wilber JF, Coulter JD (1983) Descending serotonergic, peptidergic and cholincrgic pathways from the raphe nuclei: a multiple transmitter complex. Brain Res 288:3348.

Byrum CE, Guyenet PG (1987) Afferent and efferent connections of the A5 noradrenergic cell group in the rat. J Comp Neurol 261:529542.

Byrum CE, Stornetta R, Loewy AD (1984) Electrophysiological properties of spinally-projecting A5 noradrenergic neurons. Brain Res 303 : $15-29$.

Ceccatelli S, Millhorn DE, Hokfelt T, Goldstein M (1989) Evidence for the occurrence of an enkephalin-like peptide in adrenaline and noradrenaline neurons of the rat medulla oblongata. Exp Brain Res 74:631-640.

Charlton CG, Helke CJ (1987) Substance P-containing medullary projections to the intermediolateral cell column: identification with retrogradely transported rhodamine-labeled latex microspheres and immunohistochemistry. Brain Res 418:245-254.

Charney Y, Leger L, Dray F, Berod A, Jouvet M, Pujol JF, Dubois PM (1982) Evidence for the presence of enkephalin in catecholaminergic neurons of the cat locus coeruleus. Neurosci Lett 30:147-151.

Coote JH (1985) Noradrenergic projections to the spinal cord and their role in cardiovascular control. J Auton Nerv Sys 13:255-262.

Dahlstrom A, Fuxe K (1964) Evidence for the existence of monoamine-containing neurons in the central nervous system. I. Demonstration of monoamines in the cell bodies of brain stem neurons. Acta Physiol Scand 62:[Suppl 232]1-80.

Dalsgaard C-J, Hokfelt T, Elfvin L-G, Terenius L (1982) Enkephalincontaining sympathetic preganglionic neurons projecting to the inferior mesenteric ganglion: evidence from combined retrograde tracing and immunohistochemistry. Neuroscience 7:2039-2050.

Delle M, Thoren P (1987) Changes in sympathetic nerve activity during morphine abstinence. Acta Physiol Scand 130:47-54.

Delle M, Ricksten S-E, Haggendal J, Olsson K, Skarphedinsson JO, Thoren P (1990) Regional changes in sympathetic nerve activity and baroreceptor reflex function and arterial plasma levels of catecholamines, renin and vasopressin during naloxone-precipitated morphine withdrawal in rats. J Pharmacol Exp Ther 253:646-654.

Elde R, Hokfelt T, Johansson O, Ljungdahl A, Nilsson G, Jeffcoate SL (1978) Immunohistochemical localisation of peptides in the nervous system. In: Centrally acting peptides (Hughes J, ed), pp 17-35. London: Macmillan.

Fallon JH, Leslie F (1986) Distribution of dynorphin and enkephalin peptides in the rat brain. J Comp Neurol 249:293-336.

Finley JCW, Maderdrut JL, Petrusz P (1981) The immunohistochemical localization of enkephalin in the central nervous system of the rat. J Comp Neurol 198:541-565.

Franz DN, Hare BD, McCloskey KL (1982) Spinal sympathetic neurons: possible sites of opiate withdrawal suppression by clonidine. Science 215:1643-1645.

Fritschy J-M, Grzanna R (1990) Demonstration of two separate descending noradrenergic pathways to the rat spinal cord: evidence for an intragriseal trajectory of locus coeruleus axons in the superficial layers of the dorsal horn. J Comp Neurol 291:553-582.

Fritschy J-M, Lyons WE, Mullen CA, Kosofsky BE, Molliver ME, Grzanna R (1987) Distribution of locus coeruleus axons in the rat spinal cord: a combined anterograde transport and immunohistochemical study. Brain Res 437:176-180.

Fulwiler CE, Saper CB (1984) Subnuclear organization of the efferent connections of the parabrachial nucleus in the rat. Brain Res Bull 7: 229-259.

Gebber GL, Barman SM (1985) Latcral tcgmental ficld ncurons of cat medulla: a potential source of basal sympathetic nerve discharge. J Neurophysiol 54:1498-1512.

Gebber GL, Barman SM (1988) Studies on the origin and generation of sympathetic nerve activity. Clin Exp Hyperten A 10:[Suppl 1]3344.

Gebber GL, Barman SM, Kocsis B (1990) Coherence of medullary unit activity and sympathetic nerve discharge. Am J Physiol 259: R561-R571. 
Glazer EJ, Basbaum AI (1981) Immunohistochemical localization of leucine-enkephalin in the spinal cord of the cat: enkephalin-containing marginal neurons and pain modulation. J Comp Neurol 196:377389.

Guyenet PG, Young BS (1987) Projections of nucleus paragigantocellularis lateralis to locus coeruleus and other structures in rat. Brain Res 406:171-184.

Hokfelt T, Elde R, Johansson O, Terenius L, Stein L (1977a) The distribution of enkephalin-immunoreactive cell bodies in the rat central nervous system. Neurosci Lett 5:25-31.

Hokfelt T, Ljungdahl A, Terenius L, Elde R, Nilsson G (1977b) Immunohistochemical analysis of peptide pathways possibly related to pain and analgesia: enkephalin and substance P. Proc Natl Acad Sci USA 74:3081-3085.

Hokfelt T, Terenius L, Kuypers HGJM, Dann O (1979) Evidence for enkephalin immunoreactive neurons in the medulla oblongata projecting to the spinal cord. Neurosci Lett 14:55-60.

Holstege G, Kuypers HGJM, Boer RC (1979) Anatomical evidence for direct brain stem projections to the somatic motoneuronal cell groups and autonomic preganglionic cell groups in cat spinal cord. Brain Res 171:329-333.

Johansson O, Hokfelt T, Elde RP, Schultzberg M, Terenius L (1978) Immunohistochemical distribution of enkephalin neurons. In: Advances in biochemical psychopharmacology (Costa E, Trabucchi M, eds), pp 51-70. New York: Raven.

Katz LC, Burkhalter A, Dreyer WJ (1984) Fluorescent latex microspheres as a retrograde neuronal marker for in vivo and in vitro studies of visual cortex. Nature 310:498-500.

Khachaturian H, Lewis ME, Watson SJ (1983) Enkephalin systems in diencephalon and brainstem of the rat. J Comp Neurol 220:310320.

Krukoff TL, Ciriello J, Calaresu FR (1985) Segmental distribution of peptide-like immunoreactivity in cell bodies of the thoracolumbar sympathetic nuclei of the cat. J Comp Neurol 240:90-102.

Kuypers HGJM (1981) Anatomy of descending pathways. In: Handbook of physiology - the nervous system II (Brooks VB et al., eds), pp 597-666. Bethesda, MD: American Physiological Society.

Leger L, Charngay Y, Dubois PM, Jouvet M (1986) Distribution of enkephalin-immunoreactive cell bodies in relation to serotonin neurons in the raphe nuclei of the cat: immunohistochemical evidence for the coexistence of enkephalins and serotonin in certain cells. Brain Res 362:63-73.

Leong SK, Shieh JY, Wong WC (1984) Localizing spinal cord-projecting neurons in adult albino rats. J Comp Neurol 228:1-17.

Li S-J, Zhang X, Ingenito AJ (1988) Depressor and bradycardic effects induced by spinal subarachnoid injection of $\mathrm{D}-\mathrm{Ala}^{2}-\mathrm{D}-\mathrm{Leu}^{5}$-enkephalin in rats. Neuropeptides 12:81-88.

Loewy AD (1981) Raphe pallidus and raphe obscurus projections to the intermediolateral cell column in the rat. Brain Res 222:129-133.

Loewy AD, Burton H (1978) Nuclei of the solitary tract: efferent projections to the lower brain stem and spinal cord of the cat. J Comp Neurol 181:421-450.

Loewy AD, McKellar S (1981) Serotonergic projections from the ventral medulla to the intermediolateral cell column in the rat. Brain Res 211:146-152.

Loewy AD, McKellar S, Saper CB (1979) Direct projections from the A5 catecholamine cell group to the intermediolateral cell column. Brain Res 174:309-314.

Loewy AD, Wallach JH, McKellar S (1981) Efferent connections of the ventral medulla oblongata in the rat. Brain Res Rev 3:63-80.

Loughlin SE, Foote SL, Grzanna R (1986) Efferent projections of nucleus locus coeruleus: morphological subpopulations have different efferent targets. Neuroscience 18:307-319.

Lundberg JM, Rudehill A, Sollevi A, Theodorsson-Norheim, E, Hamberger B (1986) Frequency- and reserpine-dependent chemical coding of sympathetic transmission: differential release of noradrenaline and neuropeptide $Y$ from pig spleen. Neurosci Lett 63:96-100.

Marson L, Kiritsy-Roy JA, Van Loon GR (1989) Mu-opioid peptide modulation of cardiovascular and sympathoadrenal responses to stress. Am J Physiol 257:R901-R908.

McKellar S, Loewy AD (1982) Efferent projections of the A1 catecholamine cell group in the rat: an autoradiographic study. Brain Res 241:11-29.

Menetrey D, Basbaum AI (1987) The distribution of substance P-, enkephalin- and dynorphin-immunoreactive neurons in the medulla of the rat and their contribution to bulbospinal pathways. Neuroscience 23:173-187.

Merchenthaler I, Maderdrut JL, Altschuler A, Petrusz P (1986) Immunocytochemical localization of proenkephalin-derived peptides in the central nervous system of the rat. Neuroscience 17:325-348.

Millhorn DE, Hokfelt T, Seroogy K, Ocrtel W, Verhofstad AAJ, Wu J-Y (1987) Immunohistochemical evidence for colocalization of $\gamma$-aminobutyric acid and serotonin in neurons of the ventral medulla oblongata projecting to the spinal cord. Brain Res 410:179-185.

Morita Y, Zhang J-H, Hironaka T, Tateno E, Noguchi K, Sato M, Kiyama H, Tohyama M (1990) Postnatal development of preproenkephalin mRNA containing neurons in rat lower brainstem. J Comp Neurol 292:193-213.

Naranjo JR, Urdin MC, Borrell J, Fuentes JA (1986) Evidence for a central but not adrenal, opioid mediation in hypertension induced by brief isolation in the rat. Life Sci 38:1923-1930.

Newman DB (1985) Distinguishing rat brainstem reticulospinal nuclei by their neuronal morphology. I. Medullary nuclei. J Hirnforsch 26: 187-226.

Nordin M, Morat P, Zainora M (1987) The effect of endogenous opioids on blood pressure during stress. Clin Exp Pharmacol Physiol 14:303-308.

Palkovits M, Jacobowitz DM (1974) Topographic atlas of catecholamine and acetylcholinesterase-containing neurons in the rat brain. J Comp Neurol 157:29-42.

Paxinos G, Watson G (1982) The rat brain in stereotaxic coordinates. Sydney: Academic.

Pellegrino LJ, Cushman AJ (1967) A stereotaxic atlas of the rat brain. New York: Appleton-Century-Crofts.

Petras JM, Cummings JF (1972) Autonomic neurons in the spinal cord of the rhesus monkey: a correlation of the findings of cytoarchitectonics and sympathectomy with fiber degeneration following dorsal rhizotomy. J Comp Neurol 146:189-218.

Rochford J, Henry JL (1990) Intrathecal administration of delta receptor agonists in the urethane anesthetized rat provokes an arterial pressure via a non-opioid mechanism. Brain Res 512:259-268.

Romagnano MA, Hamill RW (1984) Spinal sympathetic pathway: an enkephalin ladder. Science 225:737-739.

Romagnano MA, Braiman J, Loomis M, Hamill RW (1987) Enkephalin fibers in autonomic nuclear regions: intraspinal vs. supraspinal origin. J Comp Neurol 266:319-331.

Romagnano MA, Harshberger R, Saper CB, Hamill RW (1988) Enkephalinergic projections from the brainstem to the spinal cord. Soc Neurosci Abstr 14:1316.

Ross CA, Armstrong DM, Ruggiero DA, Pickel VM, Joh TH, Reis DJ (1981) Adrenaline neurons in the rostral ventrolateral medulla innervate thoracic spinal cord: a combined immunocytochemical and retrograde transport demonstration. Neurosci Lett 25:257-262.

Ross CA, Ruggiero DA, Joh TH, Park DH, Reis DJ (1984) Rostral ventrolateral medulla: selective projections to the thoracic autonomic cell column from the region containing $\mathrm{C} 1$ adrenaline neurons. $\mathrm{J}$ Comp Neurol 228:168-185.

Saper CB, Loewy AD (1980) Efferent connections of the parabrachial nucleus in the rat. Brain Res 197:291-317.

Sar M, Stumpf WE, Miller RJ, Chang K-J, Cuatrecasas P (1978) Immunohistochemical localization of enkephalin in rat brain and spinal cord. J Comp Neurol 182:17-38.

Sasek CA, Helke CJ (1989) Enkephalin-immunoreactive neuronal projections from the medulla oblongata to the intermediolateral cell column: relationship to substance P-immunoreactive neurons. J Comp Neurol 287:484-494.

Sasek CA, Wessendorf MW, Helke CJ (1990) Evidence for co-existence of thrytropin-releasing hormone, substance $P$ and serotonin in ventral medullary neurons that project to the intermediolateral cell column in the rat. Neuroscience 35:105-119.

Senba E, Shiosaka S, Hara Y, Inagaka S, Sakanaka M, Tohyama M (1982) Ontogeny of the peptidergic system in the rat spinal cord: immunohistochemical analysis. J Comp Neurol 208:54-66.

Skagerberg G, Bjorklund A (1985) Topographic principles in the spinal projections of serotonergic and non-serotonergic brainstem neurons in the rat. Neuroscience 15:445-480.

Stanfield BB (1989) Evidence that dorsal locus coeruleus neurons can maintain their spinal cord projection following neonatal transection of the dorsal adrenergic bundle in rats. Exp Brain Res 78:533-538.

Sundberg DK, Dunlap D (1986) Methods for estimating a contribution 
of proenkephalin A and proenkephalin B input to neuronal areas. In: Methods in enzymology, Vol 124 (Conn PM, ed), pp 617-627. New York: Academic.

Tohyama M, Sakai K, Touret M, Salvert D, Jouvet M (1979) Spinal projections from the lower brain stem in the cat as demonstrated by the horseradish peroxidase technique. II. Projections from the dorsolateral pontine tegmentum and raphe nuclei. Brain Res 176:215231

Uhl GR, Goodman RR, Kuhar MJ, Childers SR, Snyder SH (1979) Immunohistochemical mapping of enkephalin containing cell bodies, fibers and nerve terminals in the brainstem of the rat. Brain Res 166: 75-94.
Westlund KN, Bowker RM, Ziegler MG, Coulter JD (1981) Origins of spinal noradrenergic pathways demonstrated by retrograde transport of antibody to dopamine- $\beta$-hydroxylase. Neurosci Lett 25:243249.

Westlund KN, Bowker RM, Ziegler MG, Coulter JD (1982) Descending noradrenergic projections and their spinal terminations. In: Progress in brain research, Vol 57 (Kuypers HGJM, Martin GM, eds), pp 219-236. Amsterdam: Elsevier/North-Holland.

Westlund KN, Bowker RM, Ziegler MG, Coulter JD (1983) Noradrenergic projections to the spinal cord of the rat. Brain Res 263:1531. 